\title{
Bases moleculares e celulares das nefropatias hereditárias císticas
}

\author{
Molecular basis of hereditary cystic kidney diseases
}

\author{
Andressa Godoy Amaral ${ }^{1}$, Luiz Fernando Onuchic ${ }^{2}$
}

Amaral AG, Onuchic LF. Bases moleculares e celulares das nefropatias hereditárias císticas / Molecular basis of hereditary cystic kidney diseases. Rev Med (São Paulo). 2015 set.-dez.;94(4):263-81.

RESUMO: As nefropatias hereditárias císticas (NHCs) são causadas por mutações gênicas determinantes ao desenvolvimento de anormalidades nas células renais epiteliais, alterações que criam as condições biológicas necessárias à formação cística. A identificação de genes mutados nessas enfermidades e a caracterização de seus produtos proteicos vêm permitindo a elucidação de mecanismos envolvidos em sua patogênese. Esta revisão tem como foco as bases genéticas e a patogênese molecular dessas enfermidades, embora também aborde brevemente aspectos clínicos e epidemiológicos das NHCs de maior impacto médico e socioeconômico. Dentro deste conjunto de moléstias, abordaremos a doença renal policística autossômica dominante, doença renal policística autossômica recessiva, nefronoftises, doença renal túbulo-intersticial autossômica dominante, doença de von Hippel-Lindau e complexo esclerose tuberosa. Essas NHCs possuem sobreposição de manifestações clínicas e compartilham vias e defeitos moleculares. Entre suas características comuns, destacaremos o papel central de anormalidades no cílio apical primário e de vias de sinalização intracelular responsáveis por alterações fundamentais do fenótipo celular. Ao apresentar os avanços obtidos na patogênese molecular e celular das NHCs, discutiremos criticamente o estabelecimento, os papeis e as implicações da homeostase defeituosa de cálcio citosólico; resposta celular hiperproliferativa ao AMP cíclico; taxas elevadas de proliferação celular e apoptose; alterações da matriz extracelular; alterações da polaridade celular; e secreção transepitelial de fluido. $\mathrm{O}$ conhecimento acumulado nas últimas duas décadas trouxe um novo contexto molecular e celular às NHCs, capaz de criar a plataforma de conhecimento necessária para o desenvolvimento de ensaios pré-clínicos. Tais ensaios, por sua vez, vêm amparando a condução de estudos clínicos robustos, os quais têm aberto perspectivas terapêuticas promissoras.

Descritores: Doenças renais císticas; Mutação/genética; Rim policístico autossômico recessivo; Rim policístico autossômico dominante.

\begin{abstract}
The inherited cystic nephropathies (ICNs) are caused by gene mutations determinant to the development of renal epithelial cell abnormalities, alterations that create the biological conditions necessary to cyst formation. The identification of genes mutated in these diseases and the characterization of their protein products have been allowing the elucidation of mechanisms involved in their pathogenesis. The current review focus on the genetic basis and molecular pathogenesis of such illnesses, though it also briefly addresses clinical and epidemiological aspects of the ICNs with higher medical and socioeconomical impact. Within this disease set, we will approach autosomal dominant polycystic kidney disease, autosomal recessive polycystic kidney disease, nephronophthises, autosomal dominant tubuleinterstitial kidney disease, von Hippel-Lindau disease, and tuberous sclerosis complex. These ICNs present overlapping of clinical manifestations and share pathways and molecular defects. Among their common features, we will focus on the central role of abnormalities affecting the primary apical cilium and intracellular signaling pathways responsible for fundamental alterations in cell phenotype. When highlighting the advances in molecular and cellular pathogenesis of ICNs, we will critically discuss the establishment, the roles and the implications of the defective cytosolic calcium homeostasis; hyperproliferative cell response to cyclic AMP; high cell proliferation and apoptosis rates; extracellular matrix alterations; cell polarity abnormalities; and transepithelial fluid secretion. The knowledge accumulated in the last two decades brought a new molecular and cellular scenario to the ICNs, creating the required platform to develop preclinical assays. Such studies, in turn, have been supporting the performance of robust clinical trials which have been opening promising therapeutic perspectives.
\end{abstract}

Keywords: Kidney diseases, cystic; Mutation/genetics; Polycystic kidney autosomal recessive; Polycystic kidney autosomal dominante.

1. Mestrado em Biologia Funcional e Molecular. Técnica responsável do Laboratório de Nefrologia Celular, Genética e Molecular da Faculdade de Medicina da Universidade de São Paulo. E-mail: andressa_amaral@usp.br

2. Professor Titular da Disciplina de Medicina Molecular, Clínica Médica, Faculdade de Medicina da Universidade de São Paulo. Responsável pelo Laboratório de Nefrologia Celular, Genética e Molecular da Faculdade de Medicina da Universidade de São Paulo. E-mail: lonuchic@usp.br,

Endereço para correspondência: Luiz Fernando Onuchic. Laboratório de Nefrologia Celular, Genética e Molecular. Av. Dr. Arnaldo, 455 - $4^{\circ}$ andar, sala 4304. CEP: 01246-903. São Paulo, SP. 


\section{INTRODUÇÃO}

$\mathrm{C}$ Yerca de um terço da população acima de 50 anos de idade apresenta cistos renais. Embora na maior parte desses casos esta manifestação ocorra na forma de cistos simples, o acometimento cístico renal também inclui doenças císticas de maior complexidade, associadas a múltiplas etiologias e expressão fenotípica altamente variável ${ }^{1}$. Tais desordens podem ser causadas por mutações germinativas patogênicas, como nas nefropatias císticas herdadas, por anormalidades do desenvolvimento embriológico, pelo desenvolvimento de cistos associados a doenças sistêmicas e por cistos renais adquiridos ao longo da vida.

Nesta revisão abordaremos as nefropatias hereditárias císticas (NHC), um conjunto de doenças de elevado impacto médico e socioeconômico. Entre elas, destacamse a doença renal policística autossômica dominante (DRPAD), a doença renal policística autossômica recessiva (DRPAR), as nefronoftises (NPHP) e a doença renal túbulointersticial autossômica dominante (DRIAD). A DRPAD constitui-se na doença renal hereditária mais comum, sendo responsável por 4,4-10\% de todos os pacientes em terapia renal substitutiva em todo mundo ${ }^{2}$. A DRPAR é uma moléstia renal cística geralmente grave e de início precoce, consistindo em uma importante causa hereditária de doença renal crônica terminal (DRCT) na infância ${ }^{3}$. As NPHPs, por sua vez, constituem as causas mais comuns de DRCT em crianças e adultos jovens ${ }^{4,5}$. A patogênese molecular e celular dessas enfermidades será abordada com relativa profundidade neste artigo, em conjunto com seus aspectos clínicos e epidemiológicos, estes de forma menos detalhada. A DRIAD manifesta-se clinicamente entre a terceira e sexta década de vida, evoluindo para DRCT em idades variadas ${ }^{6}$. Esta desordem será discutida de forma mais sucinta, assim como a doença de von Hippel-Lindau (VHL) e complexo esclerose tuberosa (CET).

As NHCs têm como base comum mutação ou mutações germinativas em um locus ou loci gênicos determinantes para o desenvolvimento de desordens estruturais e/ou funcionais em células renais epiteliais. Este defeito gênico primário resulta na dilatação e/ou evaginação a partir de segmentos tubulares, processo que progride à formação e crescimento gradual de cistos renais e, frequentemente, ao declínio da função renal. Embora a cistogênese envolva um mecanismo complexo e com particularidades para cada entidade patológica, avanços obtidos nas últimas duas décadas foram capazes de identificar defeitos moleculares e celulares comuns à formação e à expansão dos cistos renais. Tais mecanismos compreendem homeostase defeituosa de cálcio citosólico, resposta celular hiperproliferativa ao AMP cíclico (AMPc), taxas elevadas de proliferação celular e apoptose, alterações da matriz extracelular, alterações da polaridade celular, secreção transepitelial de fluidos, desdiferenciação celular e inflamação. As vias moleculares envolvidas nessas alterações celulares serão apresentadas ao longo desta revisão.

A identificação de muitos genes mutados nas NHCs, ocorrida a partir da década de 90 , abriu um novo cenário na investigação da patogênese dessas doenças, permitindo a caracterização das proteínas codificadas por tais genes e a geração de modelos animais ortólogos às enfermidades humanas. Interessantemente, muitos dos produtos de genes mutados em doenças císticas renais humanas e em modelos animais de doença renal policística se expressam no cílio apical primário (CAP). Dessa forma, foi possível unificar um amplo espectro de doenças císticas renais sob um novo conceito fisiopatológico denominado "ciliopatias". No entanto, apesar dos grandes avanços obtidos as relações entre defeitos no CAP e cistogênese ainda são pouco compreendidas.

O CAP, classificado como cílio não-móvel, é uma organela sensorial que se projeta da superfície da grande maioria das células. Esta estrutura assume um papel fundamental na sinalização celular, incluindo vias envolvidas no crescimento e diferenciação celular, orientação tridimensional da polaridade celular e divisão planar, proliferação celular e apoptose. Dada a amplitude de tal modulação, disfunções de vias que transitam pelo CAP podem resultar em fenótipos complexos e afetar múltiplos órgãos; notavelmente, entretanto, o achado clinico mais comum das ciliopatias é o desenvolvimento de cistos renais ${ }^{7}$. Embora disfunções de proteínas expressas no CAP resultem em cistogênese, defeitos em proteínas não ciliares também podem levar à formação de cistos renais. Ademais, a localização subcelular de muitas cistoproteínas não é restrita ao CAP. Estudos recentes apoiam, de fato, o envolvimento de vias de sinalização extraciliares no processo de cistogênese e demonstram interações e modulações entre diferentes cistoproteínas, convergindo a um fenótipo cístico comum.

\section{DOENCA RENAL POLICÍSTICA AUTOSSÔMICA DOMINANTE (DRPAD)}

\section{Epidemiologia e Manifestações Clínicas}

A DRPAD é uma das doenças hereditárias humanas mais comuns, com uma prevalência estimada de 1:400$1000 \mathrm{em}$ diferentes populações ${ }^{8}$. Embora essa enfermidade apresente um fenótipo renal predominante, a mesma constitui-se numa doença sistêmica. Seu fenótipo renal característico inclui cistos renais múltiplos, distribuídos bilateral e difusamente. Os cistos se originam inicialmente como uma evaginação conectada ao lúmen tubular, estrutura que se desconecta do segmento de origem ao atingir um determinado tamanho. Vale notar que a doença progride com crescimento do volume dos rins e relativa 
manutenção da função renal por muitos anos, antes de iniciar um processo de declínio constante da taxa de filtração glomerular (TFG). Nesse cenário, cerca da metade dos pacientes afetados evolui para DRCT até a sexta década de vida.

A maioria dos sintomas observados nos indivíduos com DRPAD se relaciona ao aumento do tamanho dos rins e o crescimento cístico. Enquanto dor em flanco, lombar ou abdominal e plenitude pós-prandial decorrem do aumento do volume do órgão, hematúria, infecção urinária, nefrolitíase e distúrbios de concentração urinária se associam classicamente à expansão dos cistos renais.

Apesar do fenótipo renal se destacar, a DRPAD é uma desordem sistêmica, associando-se também a manifestações extra-renais. Entre estas, merecem destaque: 1) manifestações cardíacas, como prolapso da valva mitral e outras valvopatias cardíacas, aneurismas intracranianos, aneurismas aórticos, hipertrofia do ventrículo esquerdo e miocardiopatia; 2) manifestações gastrointestinais, como cistos hepáticos (com acentuado alargamento do órgão em alguns casos), cistos pancreáticos e divertículos de cólon; e 3) outras manifestações, incluindo cistos na vesícula seminal e epidídimo, hérnias abdominais e cistos esplênicos ${ }^{9,10}$.

Diversos estudos mostram que o envolvimento cardiovascular parece se iniciar precocemento no curso da DRPAD e se constitui na maior causa de morbidade e mortalidade em pacientes com a doença $a^{11,12}$. Nesse contexto, destacam-se os efeitos da hipertensão arterial sistêmica (HAS), presente em cerca de $60 \%$ dos pacientes com DRPAD antes mesmo de prejuízos na função renal serem detectados ${ }^{13,14}$ e 10 anos antes que na população geral $^{15}$. A gênese da HAS ainda não está completamente elucidada na DRPAD, porém a ativação do sistema renina-angiotensina-aldosterona (SRAA) em resposta à compressão vascular decorrente da distensão dos cistos parece cumprir um papel central na determinação desse fenótipo $^{16}$. O desenvolvimento de hipertrofia ventricular esquerda e de miocardiopatia dilatada idiopática também impactam no prognóstico da doença ${ }^{17,18}$. Em estudo recente conduzido em camundongos, mostramos que a deficiência de atividade de $P k d 1$, ortólogo ao gene humano PKD1, determinou disfunção e redução da deformidade cardíaca (strain). Foi interessante observar que o tecido cardíaco dos animais deficientes em $P k d l$ apresentou aumento de apoptose e fibrose discreta ${ }^{19}$.

\section{Os genes mutados na DRPAD e seus produtos}

A DRPAD é geneticamente heterogênea, podendo decorrer de mutações no gene PKD1 (Polycystic Kidney Disease 1), localizado no cromossomo 16p13.3, ou PKD2 (Polycystic Kidney Disease 2), mapeado à região cromossômica 4q21. Estima-se que cerca de $75 \%$ dos casos devem-se a mutações em PKD1 (DRPAD1), enquanto aproximadamente $25 \%$ dos pacientes desenvolvem a doença em decorrência de mutações em PKD2 (DRPAD2) ${ }^{20}$. De acordo com o banco de dados de mutações na DRPAD, 1272 variantes patogênicas já foram descritas para $P K D 1$ e 202 para $P K D 2$. Embora as manifestações clínicas sejam comuns à DRPAD1 e DRPAD2, pacientes com mutação em $P K D 2$ apresentam fenótipo clínico mais brando que aqueles com mutação em $P K D 1$. De fato, DRCT ocorre em média aos 54 anos na DRPAD1 versus 74 anos na DRPAD2 ${ }^{21}$.

A expressão clínica da DRPAD é bastante variada, podendo se manifestar raramente já na vida intrauterina, com rins massivamente aumentados, até apresentações brandas com função renal relativamente preservada até a sétima década de vida. Merece atenção, ainda, a observação de uma variabilidade fenotípica substancial entre e dentro de famílias afetadas. Nesse contexto, apesar de ser uma doença monogênica de transmissão genética dominante, a DRPAD se comporta como uma desordem complexa, uma vez que vários fatores genéticos e não-genéticos podem influenciar seu desfecho clínico ${ }^{22}$. Além do locus envolvido e de fatores ambientais, também contribuem para a variabilidade clínica da doença o background genético, a heterogeneidade alélica e variantes genéticas de loci modificadores ${ }^{23}$.

A inativação em homozigose de PKD1 ou PKD2 é invariavelmente embrionicamente letal. Um grande estudo de correlacão genótipo-fenótipo revelou associação entre a natureza da mutação patogênica em $P K D 1$ e a taxa de sobrevida renal. Indivíduos com mutação neste gene associada a truncamento evoluem para DCRT em média aos 55,6 anos de idade, enquanto pacientes com outros tipos de mutação atingem DRCT em média aos 67,9 anos ${ }^{23}$. Interessantemente, outro estudo relatou co-segregação de uma mutação missense para $P K D 1$ e uma mutação associada a truncamento para $P K D 2$ em três pacientes pertencentes a uma família com herança bilineal ${ }^{24}$. Esses indivíduos trans-heterozigotos sobreviveram, porém apresentaram fenótipo muito mais severo que os outros indivíduos afetados carreadores de apenas uma das mutações. Mutações que não levam à inativação completa de PKD1 ou PKD2 geram alelos hipomórficos, com diferentes níveis de atividade residual. Nesse cenário, já foram descritas casos com heterozigose composta para PKD1 ou PKD2; nesses casos, ao menos uma das variantes é necessariamente hipomórfica ${ }^{23}$.

Embora não diretamente associados à DRPAD, variantes genéticas em loci modificadores podem piorar a severidade da doença quando co-herdados com as variantes patogênicas de $P K D 1$ ou $P K D 2$. Esforços estão sendo dirigidos para a identificação de tais loci. Entre os fatores não-genéticos potencialmente capazes de influenciar a progressão da doença renal e manifestações extra-renais, destacam-se a cafeína, por favorecer a proliferação celular e secreção transepitelial de fluido, e o tabagismo, por seus efeitos potencialmente mutagênicos, 
proliferativos, inflamatórios e indutores de desbalanço redox e hemodinâmico ${ }^{25}$.

O gene PKD1 codifica policistina-1 (PC1), uma glicoproteína integral de membrana de 4.303 aminoácidos (aa) com uma porção extracelular N-terminal com mais de 3.000 aa, 11 domínios transmembrânicos e um segmento C-terminal intracelular curto de aproximadamente 200 aa. A porção extracelular N-terminal (NTF) contém uma combinação de domínios aparentemente importantes para interações proteína-proteína e proteína-carboidrato, incluindo repetições ricas em leucina; 16 cópias do domínio PKD; domínio lectina tipo-C; LDL-A(low-density lipoprotein receptor domain class A); um domínio REJ (receptor for egg jelly) e um domínio GPS ( $G$ proteincoupled receptor proteolytic site). Sua porção C-terminal apresenta diversos sítios de fosforilação e um domínio helicoidal fundamental para a interação física entre as porções C-terminais da PC1 e da policistina-2 (PC2), o produto do gene PKD2 (Figura 1). PC2 também é uma glicoproteína integral de membrana, com seis domínios transmembrânicos mas ambas as extremidades N-e C-terminais intracitosólicas (Figura 1). PC2 funciona como um canal de cátions não seletivo permeável a $\mathrm{Ca}^{2+}$, enquanto admite-se que PC1 funcione como um receptor de membrana e uma molécula de adesão.

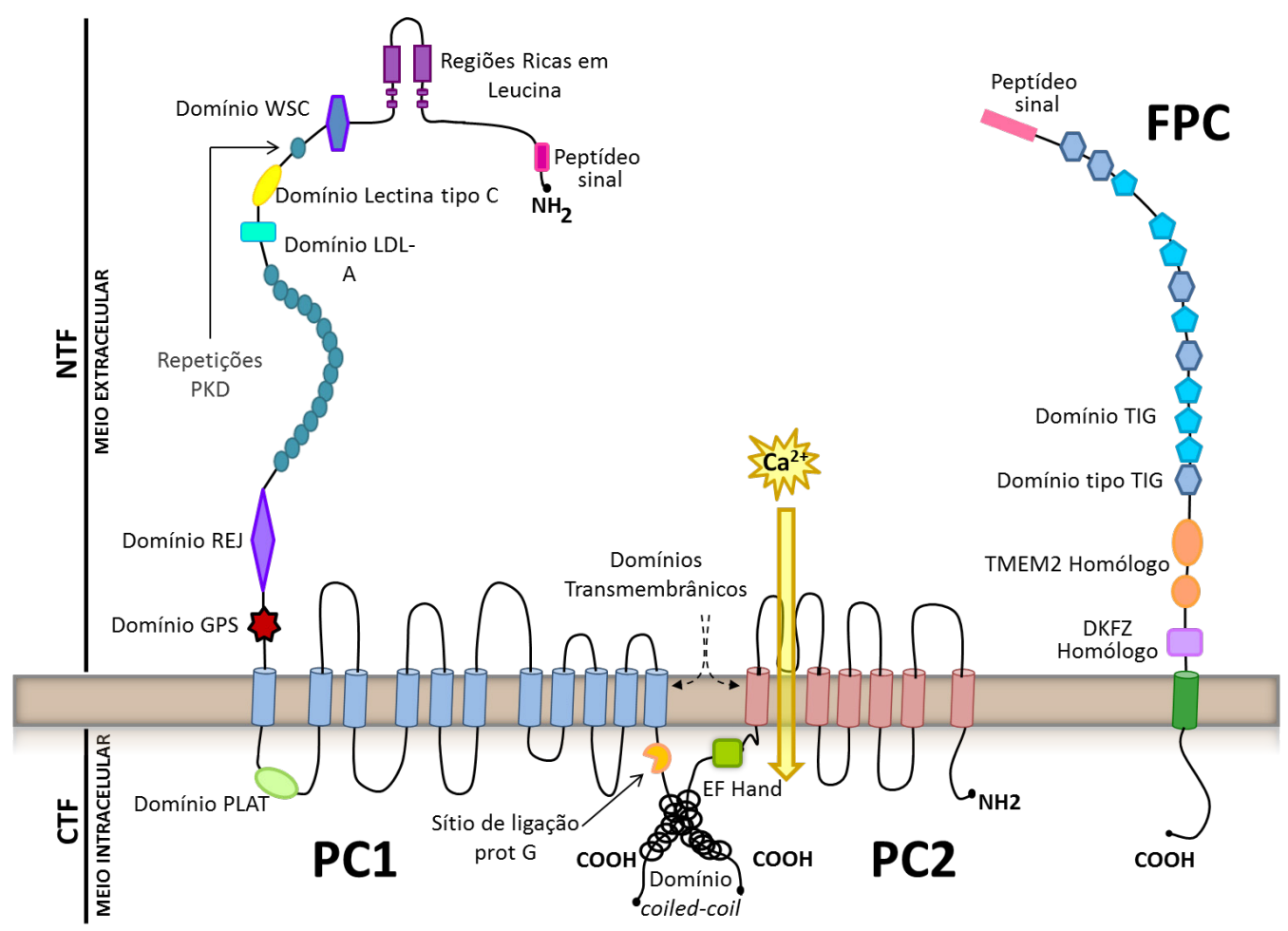

Figura 1. Estrutura e representação dos domínios fundamentais da policistina-1 (PC1), da policistina-2 (PC2) e da poliductina/fibrocistina (FPC), os produtos de $P K D 1$, PKD2, e $P K H D 1$, respectivamente. NTF: porção N-terminal da policistina-1; CTF: porção C-terminal da policistina-1

O fato de mutações em um ou outro gene induzirem fenótipos qualitativamente semelhantes apoia a formação de um complexo PC1/PC2 e modulações funcionais entre essas proteínas. Tais proteínas se expressam em muitos tecidos, porém suas funções precisas ainda são pouco conhecidas; a melhor caracterização nesse sentido foi obtida para o complexo PC1/PC2 expresso no CAP de células renais.

\section{DOENCA RENAL POLICISTICA AUTOSSÔMICA RECESSIVA (DRPAR)}

\section{Epidemiologia e Manifestações Clínicas}

A DRPAR é uma desordem caracterizada por dilatações fusiformes não obstrutivas dos ductos coletores renais e malformação do trato portal. Ocorre em uma frequência estimada de 1 para 20000 nascidos vivos, porém a existência de casos graves acompanhados de óbito fetal sugere uma incidência maior ${ }^{26}$.

Esta doença fibrocística apresenta um espectro clínico bastante variável, incluindo desde fenótipo neonatal grave até formas mais brandas de manifestações tardias. $\mathrm{O}$ fenótipo peri/neonatal caracteriza-se pelo desenvolvimento de oligoidrâmio devido ao baixo debito urinário, hipoplasia pulmonar, Síndrome de Potter (deformidades dos membros e anormalidades faciais) e rins acentuadamente aumentados. Estudos populacionais mostraram que a DRPAR apresenta mortalidade perinatal de aproximadamente 30\%, devido 
principalmente a insuficiência respiratória ${ }^{27}$.

As manifestações renais típicas consistem em rins hiperecogênicos, bastante aumentados, com perda da diferenciação córtico-medular devido às dilatações fusiformes dos ductos coletores. Cistos menores que $3 \mathrm{~mm}$ podem ser observados, principalmente na região medular. Um estudo retrospectivo mostrou que a taxa de sobrevida renal dos que sobrevivem ao período peri/neonatal é de $86 \%$ em 5 anos, $71 \%$ em 10 anos e diminui para $42 \%$ aos 20 anos (28). Os acometidos podem apresentar déficit de concentração urinária por efeito dilucional, com consequente hiponatremia, poliúria e polidipsia.

As alterações hepáticas associadas à DRPAR incluem fibrose hepática congênita (FHC) e alterações colangiodisplásicas, originadas pela malformação da placa ductal. Dado o remodelamento incompleto da placa ductal nesta doença, seguem-se uma ramificação biliar anormal e dilatação dos ductos biliares, que se associam à fibrose. Em alguns casos, os pacientes podem evoluir com dilatação massiva dos ductos biliares intrahepáticos de maior calibre, condição denominada doença de Caroli. A FHC progride ao longo do tempo, podendo levar à hipertensão portal grave. Como consequência, os pacientes podem apresentar inversão do fluxo hepatoportal, esplenomegalia e varizes de esôfago e do fundo gástrico ${ }^{26}$.

Cerca de dois terços dos pacientes apresentam HAS, geralmente de início precoce e muitas vezes de controle difícil. Embora a fisiopatologia da hipertensão nesta moléstia não seja completamente conhecida, a ativação do sistema renina-angiotensina-aldosterona intra-renal parece contribuir para tal manifestação ${ }^{29,30}$. Se neglicenciada, a HAS pode levar à hipertrofia ventricular e insuficiência cardíaca.

\section{O gene mutado na DRPAR e seu produto}

A DRPAR é causada por mutações em um único gene, PKHD1 (polycystic kidney and hepatic disease gene 1), mapeado na região cromossômica $6 \mathrm{p} 12.2$. PKHD1 é um gene enorme e complexo que se estende por um segmento genômico de $470 \mathrm{~kb}$ e inclui um mínimo de 86 éxons, arranjados em múltiplos transcritos alternativos resultantes de variações de splicing. Seu quadro de leitura aberto mais longo inclui 67 éxons e codifica poliductina/fibrocistina (FPC), uma proteína de membrana.

Até o momento, cerca de 750 mutações patogênicas foram identificadas ao longo de todo o gene ${ }^{6}$. Estudos populacionais mostraram que pacientes acometidos com ambas as mutações associadas ao truncamento de FPC se correlacionam com o fenótipo letal ou formas muito graves da doença. Mutações em sítios de splicing em ambos os alelos, ou associadas à mutação com truncamento, também resultam no fenótipo perinatal grave ${ }^{31}$.

A ampla variação fenotípica encontrada na DRPAR não pode ser explicada apenas com base no seu genótipo. Nesse contexto, também se deve considerar o papel de variantes em loci modificadores, fatores epigenéticos, efeitos hormonais e influências ambientais ${ }^{22,28,32}$.

A FPC é uma proteína de 4.074 aa com uma porção extracelular N-terminal de 3858 aa, um único domínio transmembrânico (TM) e uma cauda C-terminal intracelular curta. A porção extracelular é constituída por repetições de domínios TGI/IPT (immunoglobulin-like-plexintranscription factor) e $\mathrm{PbH} 1$ (parallel $\beta$-helix 1$)^{33}$ (Figura 1). Esses domínios podem mediar ações biológicas da FPC, uma vez que podem atuar como receptor de superfície e/ ou ligantes (Figura 1). O complexo perfil de splicing de PKHD1 pode gerar produtos com diferentes combinações de domínios, resultando em proteínas com diferentes afinidades, especificidades e localizações subcelulares ${ }^{34}$. FPC se expressa em ramos do broto ureteral, ductos coletores renais e ductos biliares, um padrão consistente com as alterações anátomo-patológicas da doença ${ }^{34}$. Múltiplos estudos mostraram que, no nível subcelular, FPC se expressa no cílio apical primário de células epiteliais renais e colangiócitos ${ }^{34-36}$.

\section{NEFRONOFTISE (NPHP)}

\section{Epidemiologia e Manifestações Clínicas}

A denominação "nefronoftise" refere-se a um conjunto de desordens monogênicas de herança autossômica recessiva, caracterizadas pelo acometimento túbulo-intersticial e desenvolvimento de fibrose renal. A NPHP constitui-se na principal causa genética de DRCT em crianças e adultos jovens. Clinicamente é possível distinguir 3 diferentes formas de NPHP. Na forma mais comum de NPHP, a juvenil ou NPHP1, as manifestações clínicas podem começar antes dos 6 anos de idade e os pacientes evoluem para DRCT em média aos 13 anos. A NPHP infantil ou NPHP2 é a forma mais rara, evoluindo para DRCT antes dos 4 anos. A NPHP da adolescência ou NPHP 3, por sua vez, evolui para DRCT em média aos $19 \operatorname{anos}^{4,5,37}$.

Em estágios funcionalmente mais precoces, os pacientes com NPHP apresentam polidipsia, poliúria, defeitos de concentração urinária, enurese, natriurese e anemia. Com o curso da doença, instala-se um quadro de desidratação persistente que, juntamente com o desenvolvimento precoce de DRC, tornam o retardo de crescimento um achado comum ${ }^{38}$.

Embora o fenótipo renal possa variar consideravelmente entre as diferentes formas clínicas de NPHP, características comuns são compartilhadas. Em exames ultrassonográficos, pacientes com NPHP apresentam rins de tamanho usualmente normal ou diminuído, com perda da diferenciação córtico-medular e presença de pequenos cistos córtico-medulares. Além disso, a NPHP apresenta como características histológicas renais atrofia tubular, infiltrado inflamatório, fibrose intersticial e alterações na espessura e/ou rompimento da membrana basal tubular ${ }^{1,4,5}$.

Cerca de $10-20 \%$ dos pacientes desenvolvem manifestações extra-renais, principalmente visuais, neurológicas e ósteo-musculares. Os genes mutados na NPHP codificam proteínas envolvidas na atividade primária do $\mathrm{CAP}^{4,39}$. Uma vez que o CAP está presente em diferentes tipos celulares, defeitos estruturais e/ou funcionais podem afetar múltiplos órgãos, dando origem 
a diferentes síndromes. A síndrome de Senior-Loken (SLS) é caracterizada pela associação das manifestações renais típicas da NPHP com retinite pigmentosa, a manifestação extrarrenal mais comum associada a essa desordem $^{40}$. Pacientes com manifestações neurológicas podem apresentar síndrome de Joubert (SJ), associada à hipoplasia de vermis cerebelar e ataxia, assim como síndrome de Meckel-Gruber (MKS), geralmente letal, associada à encefalocele occipital, polidactilia e displasia renal bilateral ${ }^{40}$. Outras síndromes menos comuns também já foram relacionadas à NPHP. Vale notar, ainda, que tais manifestações podem por vezes se expressar isoladamente, sem envolvimento renal ${ }^{1,5,40}$.

\section{Os genes mutados nas NPHPs e seus produtos}

A NPHP é geneticamente muito heterogênea; 20 genes mutados nessa entidade já foram identificados até $o$ momento: NPHP1-NPHP18, NPHP1L e NPHP $2 L^{40}$. Esta enfermidade constitui-se em uma desordem de herança autossômica recessiva em que deleções homozigotas no gene NPHP1 respondem por $21 \%$ dos casos. Em cerca de $70 \%$ dos indivíduos afetados, contudo, a causa genética não é conhecida. Nesse cenário, a lista de genes associados às NPHPs deve se expandir ao longo dos próximos anos.

O conjunto de proteínas codificadas por esses genes são denominadas "nefrocistinas" (NFCs) e se expressam em componentes ciliares ou em estruturas associadas ao CAP, como corpúsculo basal e centrossomos ${ }^{4,39}$. As NFCs participam da ciliogênese e da regulação de vias de sinalização ciliares envolvidas em proliferação e orientação celular, principalmente nos rins, retina, ossos e sistema nervoso central ${ }^{1,5}$. A Tabela 1 sumariza os genes mutados nas NPHPs, suas localizações cromossômicas, suas respectivas proteínas, o fenótipo renal (idade média de DRCT) e os fenótipos extrarrenais/síndromes a que se associam.

Tabela 1: Genes mutados nas nefronoftises e seus respectivos produtos gênicos, fenótipo renal e manifestações extrarrenais/síndromes associadas

\begin{tabular}{|c|c|c|c|c|}
\hline Gene Mutado & Proteína & Cromossomo & $\begin{array}{l}\text { Fenótipo renal (idade } \\
\text { média de DRCT) }\end{array}$ & Manifestações extrarenais \\
\hline NPHPl & Nefrocistina-1 & $2 q 13$ & NPHP (13 anos) & $\begin{array}{l}\text { SLS ( } 10 \%), \text { AOM }(2 \%), \text { JBTS } \\
\text { (raramente) }\end{array}$ \\
\hline NPHP2/INVS & Inversina & $9 \mathrm{q} 31$ & NPHP Infantil (<4 anos) & $\begin{array}{l}\text { SLS (10\%), FH, situs inversus, } \\
\text { DCC }\end{array}$ \\
\hline NPHP3 & Nefrocistina-3 & $3 q 22$ & $\begin{array}{l}\text { NPHP Infantil e da } \\
\text { Adolescência }\end{array}$ & $\begin{array}{l}\text { FH, SLS (10\%), situs inversus, } \\
\text { MKS, DCC }\end{array}$ \\
\hline NPHP4 & Nefrocistina-4 & $1 \mathrm{p} 36$ & NPHP (21 anos) & SLS (10\%), AOM, FH \\
\hline NPHP5/IQCB1 & Nefrocistina-5 & $3 \mathrm{q} 21$ & NPHP (13 anos) & SLS de início precoce \\
\hline NPHP6/CEP290 & Nefrocistina-6/CEP290 & $12 \mathrm{q} 21$ & NPHP & JBTS, MKS, SLS \\
\hline NPHP7/GLIS2 & Nefrocistina-7/GLIS2 & $16 \mathrm{p}$ & NPHP & - \\
\hline NPHP8/RPGRIP1L & Nefrocistina-8/RPGRIP1L & $16 \mathrm{q}$ & NPHP & JBTS, MKS, SLS \\
\hline NPHP9/NEK8 & Nefrocistina-9/NEK8 & $17 \mathrm{q} 11$ & NPHP Infantil (<4 anos) & SLS \\
\hline NPHP10/SDCCAG8 & Nefrocistina-10/SDCCAG8 & $1 \mathrm{q} 43$ & NPHP Juvenil & SLS, BBS-like \\
\hline TMEM67/MKS3/NPHP11 & Nefrocistina-11/Meckelin & $8 \mathrm{q} 22.1$ & NPHP & JBTS, MKS, FH \\
\hline TTC21B/JBTS11/NPHP12 & Nefrocistina-12/IFT139 & $2 \mathrm{q} 24.3$ & $\begin{array}{l}\text { NPHP de início precoce, } \\
\text { NPHP Juvenil }\end{array}$ & JATD, MKS, JBTS, BBS-like \\
\hline WDR19/NPHP13 & Nefrocistina-13/IFT144 & $4 \mathrm{p} 14$ & NPHP & JATD, SBS, SLS, Caroli, BBS-like \\
\hline ZNF423/NPHP14 & Nefrocistina-14/ZNF423 & $16 \mathrm{q} 12.1$ & NPHP Infantil, PKD & JBTS, situs inversus \\
\hline CEP164/NPHP15 & $\begin{array}{l}\text { Nefrocistina-15/centrosomal } \\
\text { protein } 164 \mathrm{kDa}\end{array}$ & $11 \mathrm{q} 23.3$ & NPHP (8 anos) & SLS, JBTS, FH, obesidade \\
\hline ANKS6/NPHP16 & Nefrocistina-16/ANKS6 & $9 \mathrm{q} 22.33$ & NPHP, PKD & $\begin{array}{l}\text { FH, situs inversus, anormalidades } \\
\text { cardiovasculares }\end{array}$ \\
\hline IFT172/NPHP17 & Nefrocistina-17/IFT172 & $2 \mathrm{p} 23.3$ & NPHP & JATD, JBTS \\
\hline CEP83/NPHP18 & $\begin{array}{l}\text { Nefrocistina-18/centrosomal } \\
\text { protein } 83 \mathrm{kDa}\end{array}$ & $12 \mathrm{q} 22$ & $\begin{array}{l}\text { NPHP de início precoce } \\
(3 \text { anos) }\end{array}$ & $\begin{array}{l}\text { Dificuldade de aprendizado, } \\
\text { hidrocefalia, FH }\end{array}$ \\
\hline NPHP1L/XPNPEP3 & Nefrocistina-1L/XPNPEP3 & $22 \mathrm{q} 13$ & NPHP & Cardiomiopatia, crises convulsivas \\
\hline NPHP2L/SLC41A1 & Nefrocistina-2L/SLC41A1 & $1 \mathrm{q} 32.1$ & NPHP & Bronquioectasia \\
\hline
\end{tabular}

BBS-like: semelhante à Sindrome Bardet-Biedl; DCC: doença crônica cardíaca, JATD: displasia torácica asfixiante de Jeune, JBTS: Síndrome de Joubert; FH: fibrose hepática; MKS: Síndrome de Meckel-Gruber; AOM: apraxia oculomotora; SBS: Síndrome de Sensenbrenner; SLS: Síndrome Senior-Loken. 


\section{DOENÇA RENAL TÚBULO-INTERSTICIAL AUTOSSÔMICA DOMINANTE (DRIAD)}

Anteriormente denominada doença renal medular cística, a doença renal túbulo-intersticial autossômica dominante caracteriza-se pela presença esporádica de cistos medulares, alterações tubulares e fibrose intersticial. Embora seu fenótipo renal assemelhe-se bastante ao da NPHP, a DRIAD constitui-se em uma desordem herdada de forma dominante e não se associa a manifestações extrarrenais típicas. Outra diferença importante é que a DRCT ocorre classicamente entre a terceira e sexta década de vida, ao passo que nas NPHPs ocorre antes dos 20 anos de idade.

Indivíduos acometidos pela DRIAD apresentam capacidade de concentração urinária diminuída em decorrência da nefrite intersticial. A evolução para DRCT é lenta e o exame de urina revela ausência de células sanguíneas e quantidades mínimas ou ausência de proteinúria. Em virtude do desenvolvimento de fibrose, os rins mantêm-se com tamanho normal ou o apresentam diminuído/atrofiado.

ADRIAD é uma desordem heterogênea de herança autossômica dominante, que pode decorrer de mutação em um de quatro genes: $U M O D$, que codifica a proteína uromodulina; $M U C 1$, cujo produto é denominado mucina; $R E N$, que codifica a pré-pro-renina; e HNF1 $\beta$ (hepatocyte nuclear fator $1 \beta$ ), codificador do fator nuclear de hepatócito $1 \beta$. Vale notar, contudo, que algumas famílias afetadas não apresentam mutação em qualquer desses genes, sugerindo o envolvimento de outros loci nessa doença.

\section{DRIAD associada à mutação em UMOD}

A DRIAD resultante de mutações em $U M O D$ (DRIAD2) associa-se à perda precoce de função renal, proteinúria mínima ou ausente e rins hiperecogênicos com tamanho reduzido. Os pacientes, em sua maior parte, evoluem para DRCT entre 20 e 70 anos de idade. HAS e defeitos de concentração urinária podem ser observados em uma parcela dos pacientes (1). Achados histológicos incluem fibrose túbulo-intersticial difusa e presença esporádica de cistos medulares. A hiperuricemia é um achado característico nessa desordem, podendo ser assintomática ou evoluir para gota ${ }^{41,42}$.

$U M O D$ é mapeado na região cromossômica 16 p12.3 e possui 11 éxons. Seu produto uromodulina (Umod) também é conhecida por Tamm-Horsfall, expressando-se exclusivamente nas células epiteliais da porção ascendente espessa da alça de Henle (TAL). Umod possui um alto conteúdo de resíduos cisteína que permite a formação de pontes dissulfeto e, consequentemente, a estabilização de sua estrutura terciária complexa ${ }^{43}$. Mais de 100 mutações patogênicas já foram descritas para $U M O D$ em pacientes com DRIAD. Vale notar que a maior parte delas se concentra nos éxons 4 e 5 e leva à substituição de um resíduo de cisteína ${ }^{44}$. Essa alteração não permite seu adequado empacotamento no retículo endoplasmático (RE), impedindo o tráfego de Umod para a membrana plasmática (MP $)^{45}$. Uma vez aprisionada no RE, a Umod mutante precipita e pode ativar vias de estresse de RE, morte celular por apoptose, inflamação e fibrose. A ativação destes mecanismos induz lesão na TAL, acelerando a perda de função renal ${ }^{43}$. A perda da integridade da TAL também contribui para o defeito de concentração urinária e diminuição da reabsorção de sódio nessa porção do néfron. Essa diminuição, por sua vez, é compensada pelo aumento da reabsorção desse íon nos túbulos proximais, o que favorece o aumento da reabsorção de ácido úrico e, consequente e aparentemente, a hiperuricemia característica na DRIAD2 (43). Interessantemente, Umod mutante pode atuar como uma proteína dominante negativa, impedindo o transporte e função da Umod normal. Além disso, assim como outras proteínas envolvidas nas doenças renais císticas, Umod se expressa no CAP e centrossomo de células renais ${ }^{46}$.

\section{DRIAD associada à mutação em MUC1}

A DRIAD decorrente de mutação em $M U C 1$ (DRIAD1) compartilha muitas características com a DRIAD2, incluindo o ritmo lento de progressão da doença túbulo-intersticial. Gota e hipertensão arterial, não são manifestações primárias na DRIAD1, embora possam ocorrer secundariamente à perda de função renal em estágio avançado de doença renal crônica ${ }^{47,48}$.

O gene associado à DRIAD1 foi identificado apenas em 2013. MUC1 é mapeado na região cromossômica 1q21 e, estruturalmente, possui várias cópias (20-125) de uma grande unidade de repetição (60 pares de bases) com alto conteúdo de CG $(>80 \%)$, denominada VNTR. Todas as mutações descritas para DRIAD1 até o momento compreendem uma inserção de citosina na região VNTR, resultando em mudança de fase de leitura e consequente geração de uma proteína anormal com uma unidade de repetição distinta. Devido a essas particularidades, a identificação desse tipo de mutação requer ensaios específicos e complexos ${ }^{49}$.

Muc1, o produto de gene $M U C 1$, é uma das proteínas constituintes do muco, cuja função é lubrificar e proteger epitélios de revestimento. Constitui-se em uma glicoproteína de alto peso molecular, com domínios transmembrânicos e uma cauda citoplasmática (MucT) com domínios envolvidos em sinalização celular. Acredita-se que MucT possa se desprender da membrana plasmática e migrar para o núcleo celular. Uma vez no núcleo, MucT pode regular a transcrição de genes envolvidos na proliferação, motilidade, adesão e viabilidade celular ${ }^{50}$. Seu papel na patogênese da DRIAD1, contudo, ainda é incerto. Uma possibilidade é que Muc1 aberrante não 
sofra processamento pós-translacional, perdendo suas propriedades originais de ancoramento transmembrânico e seus domínios de sinalização intracelular. A neoproteina formada pode se acumular no interior das células tubulares renais e induzir morte celular ${ }^{48}$.

\section{DRIAD associada à mutação em REN}

A DRIAD causada por mutações em REN evolui com declínio da função renal geralmente no final da adolescência e para DRCT entre 40 e 60 anos de idade $^{51}$. O acometimento renal pode vir acompanhado de hiperuricemia e gota, porém nesses casos a manifestação ocorre geralmente mais tarde, entre 20-30 anos. Nesse subtipo de DRIAD, os pacientes desenvolvem anemia em idade precoce devido aos níveis reduzidos de eritropoetina ${ }^{52}$. Ocasionalmente os pacientes podem apresentar pressão arterial diminuída e hipercalemia leve.

$R E N$ localiza-se na região cromossômica 1q32 e codifica um RNA mensageiro composto por 10 éxons, inicialmente traduzido em uma proteína intermediária denominada pré-pro-renina. Essa proteína intermediária contém um peptídeo sinal responsável por seu endereçamento ao RE. Nessa organela, a pré-pro-renina é clivada e processada até sua forma ativa. Mutações pontuais na sequência sinal impedem seu transporte e processamento no RE. Dessa forma, renina ativa não é formada e secretada, seguindo-se o acúmulo de produto mutado no citoplasma da célula $^{53,54}$. Esse acúmulo é nefrotóxico, levando à falência renal progressiva. É importante atentar que indivíduos com mutações que resultam em ausência total de renina cursam com disgenesia tubular e morte intrauterina ou em idade precoce ${ }^{55}$.

\section{DRIAD associada à mutação em HNF1ß (hepatocyte nuclear factor $1 \beta$ )}

HNF $1 \beta$ codifica um fator de transcrição associado ao desenvolvimento de vários órgãos, como pâncreas, fígado, rins e trato genito-urinário. Em rim embrionário de camundongo, Hnfl $\beta$ se expressa no broto ureteral, nos corpos em forma de vírgula, nos corpos em forma de $\mathrm{S}$ e em túbulos proximais e distais ${ }^{56}$. Mutações em $H N F 1 \beta$ foram inicialmente associadas ao desenvolvimento de uma forma precoce de diabetes mellitus (usualmente diagnosticada antes dos 25 anos de idade) denominada MODY5 (maturity onset diabetes of the young type 5). Nem todos os indivíduos com mutação em $H N F 1 \beta$ desenvolvem diabetes, porém a coexistência de cistos renais/declínio da função renal e diabetes é um fenótipo comum, denominado síndrome de cistos renais e diabetes. Nessa síndrome, os rins são hiperecogênicos e de tamanho normal ou aumentado à ultrassonografia. A variabilidade da forma de apresentação é extensa, sendo que aproximadamente $15 \%$ dos pacientes chegam à $\mathrm{DRCT}^{57}$. Mutações em $H N F 1 \beta$ também foram detectadas em casos de doença glomerulocística hipoplásica familiar associada a diabetes mellitus. Esta é uma desordem autossômica dominante caracterizada por cistos corticais glomerulares com espaçamento da cápsula de Bowman $^{58}$. A deficiência de $H N F 1 \beta$ também se associa a um amplo espectro de malformações urológicas, incluindo displasia renal, hipomagnesemia, alterações hepáticas e hiperuricemia ou gota de início precoce (1).

Deleções do gene inteiro são responsáveis por cerca de $30 \%$ das mutações de $H N F 1 \beta$, enquanto o restante consiste em mutações pontuais ${ }^{59,60}$. Vale ressaltar que 30 $50 \%$ dos casos associados a mutações nesse gene decorrem de mutações de novo, tornando seu diagnóstico desafiador ${ }^{60}$. A relação entre deficiência de $H N F 1 \beta$ e desenvolvimento de cistos renais ainda não é clara. No entanto, um estudo recente mostrou que o fator de transcrição HNF1 $\beta$ pode atuar no controle da expressão dos genes $P k h d 1, P k d 2$ e Umod $^{61}$.

\section{DOENÇA DE VON HIPPEL-LINDAU}

A doença de von Hippel-Lindau (VHL), uma síndrome neoplásica com herança autossômica dominante, afeta 1 em cada $30.000-50.000$ indivíduos ${ }^{62}$. VHL caracteriza-se pelo desenvolvimento multissistêmico de tumores benignos e malignos, e pode ser clinicamente classificada em tipo 1 ou tipo 2, consoante a ausência ou presença de feocromocitoma. A VHL tipo 2 é menos frequente, correspondendo a 7-20\% dos $\operatorname{casos}^{63}$.

Os sintomas começam a surgir em média aos 26 anos, porém o início e a forma de apresentação são muito variáveis ${ }^{64}$. As manifestações neoplásicas incluem angioglioblastomas de SNC e retina, feocromocitoma, carcinoma de células renais (CCR), tumores do saco endolinfático auditivo, cistoadenomas e neoplasias neuroendócrinas de pâncreas. A morbidade e mortalidade da VHL estão associadas às lesões neurológicas, principalmente angioglioblastomas de $\mathrm{SNC}$, e à metastização do CCR.

Cerca de $70 \%$ dos pacientes com VHL apresentam alterações morfológicas renais ${ }^{63,65}$. As manifestações nesse órgão englobam cistos, CCR e, menos frequentemente, adenomas e angiomas renais. Cistos renais podem ser simples, porém em sua maioria estão associados a componentes neoplásicos. CCRs apresentam-se como massas sólidas hipervascularizadas ou cistos complexos com septos espessos e nódulos murais. Geralmente as lesões renais são múltiplas e bilaterais, entretanto a função renal mantém-se relativamente preservada ${ }^{64}$.

A doença é causada por mutações no gene supressor de tumor $V H L$, localizado em 3 p25. Este gene é composto por 3 éxons e codifica a proteína pVHL. A associação de $\mathrm{pVHL}$ com outras proteínas leva à formação de um complexo que atua na ubiquitinação e degradação proteolítica do fator de transcrição induzível por hipóxia (HIF). HIF é formado por duas subunidades, HIF1 $\alpha$ e 
HIF $1 \beta$, que uma vez associadas dentro do núcleo da célula, se ligam a regiões específicas do DNA e ativam a transcrição de diversos genes. Em situação basal, pVHL se liga à subunidade HIF $1 \alpha$, promovendo sua ubiquitinação e degradação via proteossoma. Oxigênio e outras enzimas são cofatores para as reações envolvidas nesse processo. Em hipóxia ou na deficiência de pVHL, HIF $1 \alpha$ não é degradado e, consequentemente, migra para o núcleo, onde se associa a HIF $1 \beta^{66}$. Dentro do núcleo, HIF ativa a transcrição de genes envolvidos na proliferação celular, crescimento celular, mitose e angiogênese. A hiperativação dessas vias favorece a formação dos tumores.

\section{COMPLEXO ESCLEROSE TUBEROSA (TSC)}

O TSC é uma doença de acometimento multissistêmico, de herança autossômica dominante, causada por mutações nos genes supressores de tumor TSC1 (tuberous sclerosis 1) ou TSC2 (tuberous sclerosis 2). Essa doença apresenta incidência aproximada de 1:5800 nascidos vivos e se caracteriza pelo desenvolvimento de hamartomas, principalmente em SNC, pele, coração, pulmões e rins ${ }^{67}$.

As manifestações clínicas do TSC são altamente variáveis e dependem primariamente dos órgãos e sistemas acometidos. Elas são frequentes no SNC, estando associadas a altas taxas de morbidade e mortalidade. Entre tais manifestações, destacamos tuberosidades corticais, nódulos subependimais e astrocitoma gigante subependimal. Outra manifestação importante é a linfangioleiomiomatose pulmonar, que acomete pelo menos $40 \%$ das mulheres com TSC ${ }^{68}$. As lesões cutâneas, por sua vez, são as mais frequentes nesses pacientes, incluindo máculas hipocrômicas, fibromas ungueais e angiofibromas faciais. Embora muitos dos sintomas observados na maioria dos órgãos decorram da formação de tumores, o envolvimento neurológico pode também incluir manifestações severas não tumorais, tais como epilepsia, retardo de desenvolvimento, retardo mental, desordens de comportamento e autismo.

Cistos renais ocorrem em $14-45 \%$ dos pacientes com TSC ${ }^{69-71}$. A manifestação desse acometimento cístico pode variar da presença de microcistos assintomáticos até um fenótipo equivalente ao da DRPAD, com múltiplos cistos derivados de diferentes partes do néfron, inclusive glomérulos ${ }^{72}$. Cerca de 2-3\% dos pacientes apresentam a síndrome de contiguidade TSC2/PKD1, caracterizada por deleções envolvendo total ou parcialmente esses dois genes vizinhos. Pacientes acometidos pela síndrome de contiguidade apresentam fenótipos complexos e agressivos, que sobrepõem manifestações clínicas da TSC e da DRPAD. Nesses casos, a evolução da doença renal cística é precoce, com achados radiológicos similares aos de pacientes com DRPAD avançada ${ }^{73}$.

Os angiomiolipomas (AMLs) constituem o achado renal mais comum e geralmente estão localizados no córtex renal ${ }^{70}$. Os AMLs são hamartomas de composição histológica mista e variável, apresentando tecido adiposo, músculo liso hiperplásico e hipertrófico e exuberante vascularização. Sua incidência aumenta com a idade, chegando a acometer até $85 \%$ dos pacientes. Ao contrario dos AMLs esporádicos, são geralmente múltiplos e bilaterais ${ }^{70}$. A maior complicação associada aos AMLs é a hemorragia, uma causa capital de mortalidade na $\mathrm{TSC}^{74}$. $\mathrm{O}$ risco de sangramento aumenta com o tamanho do AML, grau de vascularização e da presença de aneurismas intratumorais ${ }^{75}$.

Aproximadamente $70 \%$ dos casos de TSC são esporádicos, decorrendo de mutações do novo. Mutações no gene $T S C 2$ são responsáveis pela maior parte dos casos $(\sim 85 \%)$ e se associam, geralmente, a um fenótipo mais grave $^{70,71}$.

TSC1 codifica hamartina, enquanto TSC 2 codifica a tuberina. Essas proteínas interagem entre si, formando um complexo funcional (TSC1/TSC2) que atua na supressão da via mTOR (mammalian target of rapamycin). mTOR é a subunidade catalítica de dois complexos funcionais, mTORC1 e mTORC2. mTORC1 é classicamente sensível à droga rapamicina e possui ação pleitrópica, regulando diversos processos celulares, como síntese proteíca, proliferação celular, crescimento celular, angiogênese e autofagia $^{76,77}$. TSC1/TSC2 inibe constitutivamente Rheb (Ras homolog enriched in brain), membro da família Ras GTPase, cuja função é ativar o complexo mTORC1. Na doença TSC, TSC1/TSC2 perde sua função inibitória, permitindo a conversão de Rheb em sua forma ativa e consequente estimulação de mTORC1. A hiperativação de mTORC1, por sua vez, favorece a formação dos tumores característicos da doença. Estudos clínicos recentes de fase 2 e 3 mostraram que tratamento com inibidores de mTOR promoveu redução de volume de tumores em SNC e rins em pacientes com $\mathrm{TSC}^{78}$. Seus benefícios de médio e longo prazo, entretanto, ainda não foram comprovados.

\section{PATOGÊNESE MOLECULAR DAS CILIOPATIAS CÍSTICAS RENAIS (DRPAD, DRPAR e NPHP)}

Cistos renais constituem o achado clinico mais comum entre as ciliopatias ${ }^{7}$. Nesse cenário, abordaremos inicialmente conceitos morfológicos e funcionais associados ao CAP para, a seguir, discutir os principais mecanismos ciliares e extra-ciliares envolvidos na patogênese molecular dessas doenças. 


\section{Cílio apical primário}

O CAP é uma organela altamente especializada que se projeta da superfície da grande maioria das células. O CAP é constituído por um axonema não dotado de motilidade, que se estende a partir de uma estrutura localizada na base do cílio denominada corpo basal (CB). Este axonema compreende nove pares de microtúbulos circundados por uma membrana; diferentemente dos cílios móveis, entretanto, não apresenta dois filamentos centrais (arranjo 9+0). O centrossomo é uma estrutura essencial na manutenção da estrutura ciliar e na ciliogênese. Ele é formado pelo centríolo mãe e pelo centríolo filho, dispostos ortogonalmente entre si. Cada centríolo, por sua vez, é formado por nove trincas de microtúbulos. Interessantemente, o CB é formado a partir do centríolo mãe em células quiescentes ou em Go. Nessa condição, o centrossomo é capaz de migrar em direção à superfície celular e se ancorar na MP. Uma vez ancorado, o centríolo mãe sofre alterações estruturais e passa a ser chamado de $\mathrm{CB}^{79}$. Interessantemente, durante a mitose os centríolos formam os pólos do fuso mitótico ${ }^{80}$.

Uma grande quantidade de estudos apoia a existência de dois mecanismos para o início da ciliogênese, a depender do tipo celular. No primeiro, a formação e projeção do CAP dependem do ancoramento do CB na $\mathrm{MP}$, enquanto no segundo o CAP começa a ser formado no citoplasma e se projeta para o meio extracelular a partir de uma invaginação da membrana chamada bolsa ciliar.

Apesar de ser uma organela contínua à membrana plasmática celular, a membrana ciliar difere substancialmente desta. Outra característica importante é a grande concentração de proteínas especializadas localizadas no CAP. As características particulares desta organela decorrem de ao menos três mecanismos singulares: 1) presença de um sistema eficiente de transporte de vesículas, que entregam e recolhem as moléculas do CAP; 2 ) presença de um 'portão' na base ciliar, capaz de selecionar a entrada e saída de moléculas; e 3) presença de um intrincado sistema de carreamento intraciliar de moléculas. Em conjunto, esses mecanismos conferem ao cílio propriedades de uma organela compartimentalizada, com alta concentração de receptores de membrana e de proteínas transdutoras de sinais.

Evidências experimentais sugerem que o transporte das proteínas ciliares ocorra através de vesículas formadas no trans-Golgi. As proteínas marcadas com peptídeo sinal ciliar são incorporadas às vesículas; ao chegarem no CAP, tais vesículas se ancoram em uma região específica da membrana ciliar e são transportadas para seu interior por exocitose polarizada ${ }^{81}$. O transporte de proteínas e lipídeos, principalmente de alto peso molecular, constitui uma questão central na formação e manutenção do CAP, embora permaneça vastamente desconhecida.

Acredita-se que a formação do 'portão ciliar' ocorra nos estágios iniciais da ciliogênese. Os microtúbulos do $\mathrm{CB}$ são ancorados à membrana ciliar pelas fibras de transição (FT). Uma vez que essas fibras encontram-se justapostas, o espaço entre elas é muito pequeno, impedindo a passagem de vesículas para dentro do $\mathrm{CAP}^{82}$. O espaço compreendido entre o $\mathrm{CB}$ e o axonema é chamado de zona de transição (ZT). Fibras em forma de Y presentes na ZT conectam os microtúbulos do axonema a uma região mais espessa da membrana ciliar, denominada colar ciliar. A ZT possui também anéis de septina, complexos proteicos aparentemente relacionados à manutenção da composição da membrana ciliar. Interessantemente, o anel de septina possui semelhanças estruturais consoantes ao complexo nuclear formador de poros. Nesse sentido, outro estudo mostrou a presença de nucleoporina na base ciliar $^{83}$. Em conjunto, essas proteínas poderiam levar à formação de poros na membrana ciliar, permitindo a passagem seletiva de moléculas ${ }^{84}$. O 'portão ciliar' abrange, portanto, tanto uma barreira física (FT) quanto uma barreira de difusão (ZT).

Além de participarem da formação do portão ciliar, FT e ZT servem como sítio de ancoramento para proteínas envolvidas na formação do axonema ${ }^{85}$. Esse processo é dependente de um intrincado sistema de transporte bidirecional, o transporte intraflagelar (IFT). O transporte de moléculas da base ciliar em direção ao axonema é denominado anterógrado e é mediado por um grande complexo de proteínas denominado IFT-B. Esse complexo é formado por ao menos 15 proteínas, além da proteína motora cinesina-2, geradora da força motriz por meio da hidrólise de moléculas de ATP. O transporte em direção à base ciliar, por sua vez, é denominado retrógrado, sendo mediado pelo complexo proteico IFT-A. Tal complexo é formado por ao menos seis proteínas, além da proteína motora dineína. Os BBSomes, complexos proteicos adicionais, parecem coordenar a transição do transporte anterógrado para o retrógado dentro do $\mathrm{CAP}^{86,87}$. Outros estudos amparam o envolvimento dos BBSomes em outras funções, como no ancoramento dos microtúbulos do $\mathrm{CB}^{88}$, na biogênese da membrana ciliar ${ }^{89}$ e na entrada e saída de proteínas específicas no $\mathrm{CAP}^{90,91}$.

Desregulações desses processos que resultem em alteração na estrutura, formação e/ou manutenção do CAP convergem para defeitos celulares fundamentais, implicados no desenvolvimento das ciliopatias. 


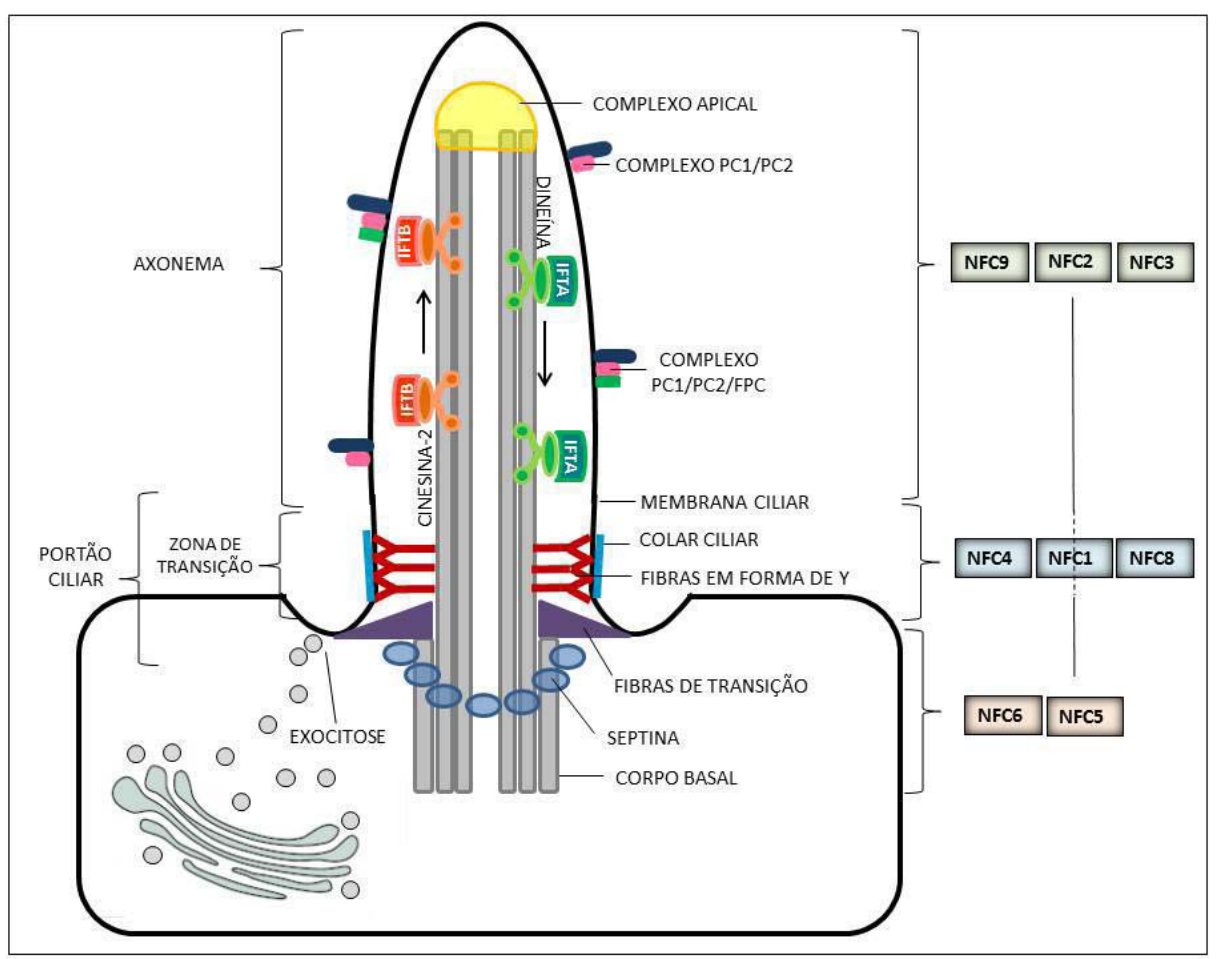

Figura 2: Estrutura do cílio apical primário. O axonema é composto por nove pares de microtúbulos que se formam a partir do corpo basal, estando envolto por uma membrana ciliar. O 'portão ciliar' é formado pelas fibras de transição e pela zona de transição. Proteínas de transporte intraflagelar (IFT) transportam moléculas para o ápice (IFT-B) e para base (IFT-A) do cílio apical primário. As proteínas motoras cinesina-2 e dineína geram a força motriz necessária ao transporte intraflagelar. Policistina-1, policistina-2 e poliductina/ fibrocistina formam um complexo funcional localizado na membrana ciliar. NFC, nefrocistina

\section{Patogênese molecular na DRPAD}

No rim, o CAP é encontrado na superfície apical de todas as células epiteliais tubulares, à exceção das células intercalares. Eles se projetam para o lúmen tubular e se curvam em resposta ao fluxo de fluido luminal. Estudos demonstraram a localização de PC1/PC2 na membrana do CAP e suportam a ideia de que esse complexo possa agir como um sensor capaz de regular diversas vias de sinalização intracelulares. Nessa linha conceitual, a porção $\mathrm{N}$-terminal de PC1 seria capaz de responder ao estímulo mecânico de curvatura do CAP, enquanto a PC2 funcionaria como um canal de cátions, permitindo o influxo celular de $\mathrm{Ca}^{2+}$. Este influxo, por sua vez, induziria liberação de $\mathrm{Ca}^{2+} \mathrm{a}$ partir de estoques intracelulares ${ }^{92,93}$. Na DRPAD, portanto, as células do epitélio de revestimento cístico apresentam uma homeostase defeituosa do $\mathrm{Ca}^{2+}$ intracelular, alteração aparentemente responsável por sua proliferação anormal em resposta ao AMPc. De fato, em células epiteliais renais normais, a proteína $\beta$-Raf é é inibida por Akt (proteína quinase dependente de $\mathrm{Ca}^{2+}$ ), prevenindo a ativação de ERK (extracellular signal-regulated kinase) por AMPc; em células DRPAD, por outro lado, AMPc estimula a via
MAPK/B-Raf/ERK (mitogen activated protein-kinase), induzindo proliferação celular ${ }^{94}$. Vale destacar que a redução do $\mathrm{Ca}^{2+}$ intracelular pode favorecer o acúmulo intracelular de AMPc, por meio da estimulação da adenil ciclase-6 e da inibição da fosfodiestarase-1 dependente de $\mathrm{Ca}^{2+} /$ calmodulina. Mostrou-se, ainda, que AMPc é capaz de estimular CFTR, um canal de cloreto presente na membrana apical de células DRPAD, promovendo secreção transepitelial de fluido dirigida por cloreto. Este mecanismo contribui para o processo de crescimento cístico ${ }^{95}$.

A expressão de $\mathrm{PC} 1$ em desmossomos, adesões focais e junções aderentes da membrana basolateral sustentam sua participação em funções extraciliares. Em células renais normais, $\mathrm{PC} 1$ forma um complexo com E-caderina e $\beta$-catenina nas junções aderentes da MP. Em células DRPAD este complexo é desarranjado e a PC1 é fosforilada. Nesse cenário, $\mathrm{PC} 1 \mathrm{e}$ E-caderina são depletadas da $\mathrm{MP}^{96}$. Em apoio a esta hipótese, outro trabalho mostrou que células DRPAD apresentam polarização anormal das proteínas de desmossomos nos domínios apical e basolatera ${ }^{97}$. Tais anormalidades contribuem para 0 
enfraquecimento da adesão celular e tornam o epitélio mais susceptível à dissociação em resposta ao estresse de cisalhamento.

Outra função das policistinas consiste na regulação do ciclo celular, ao menos parcialmente mediada pela via JAK-STAT (janus kinase- signal transducer and activator of transcription). PC1 é capaz de interagir com JAK2, que ativa o fator de transcrição STAT1, através de um processo dependente de PC2. Dímeros ativos de STAT1 migram para o núcleo, promovendo a transcrição de genes envolvidos na parada do ciclo celular em $\mathrm{G}_{0} / \mathrm{G}_{1}{ }^{98}$. A desregulação desse mecanismo pode contribuir para o aumento de proliferação celular observada na DRPAD.

Vários estudos mostraram que a via mTOR encontrase ativada no epitélio cístico renal tanto em pacientes quanto em modelos animais de DRPAD. Shillingford e cols mostraram, em células epiteliais renais, interação entre a porção C-terminal de $\mathrm{PC} 1$ e tuberina, sugerindo a formação de um complexo proteíco PC1, tuberina e mTOR ${ }^{99}$. Um estudo posterior mostrou que a interação entre a porção C-terminal de PC1 e tuberina impede a fosforilação desta pela proteína Akt, mantendo o complexo ancorado à MP e mTORC1 inibido ${ }^{100}$. Em condição normal, a formação desse complexo e seu ancoramento na membrana celular inibiria a atividade de $\mathrm{mTORC} 1$. Alterações em $\mathrm{PC} 1$ podem levar ao desarranjo desse complexo e desinibição de mTORC1 ${ }^{\text {99-101 }}$. PC1 também pode regular a via mTORC1 através da fosforilação da tuberina pela proteína ERK, liberando o efeito inibitório de TSC1/TSC2 ${ }^{102}$. As vias de sinalização alteradas da DRPAD estão esquematizadas na Figura 3.

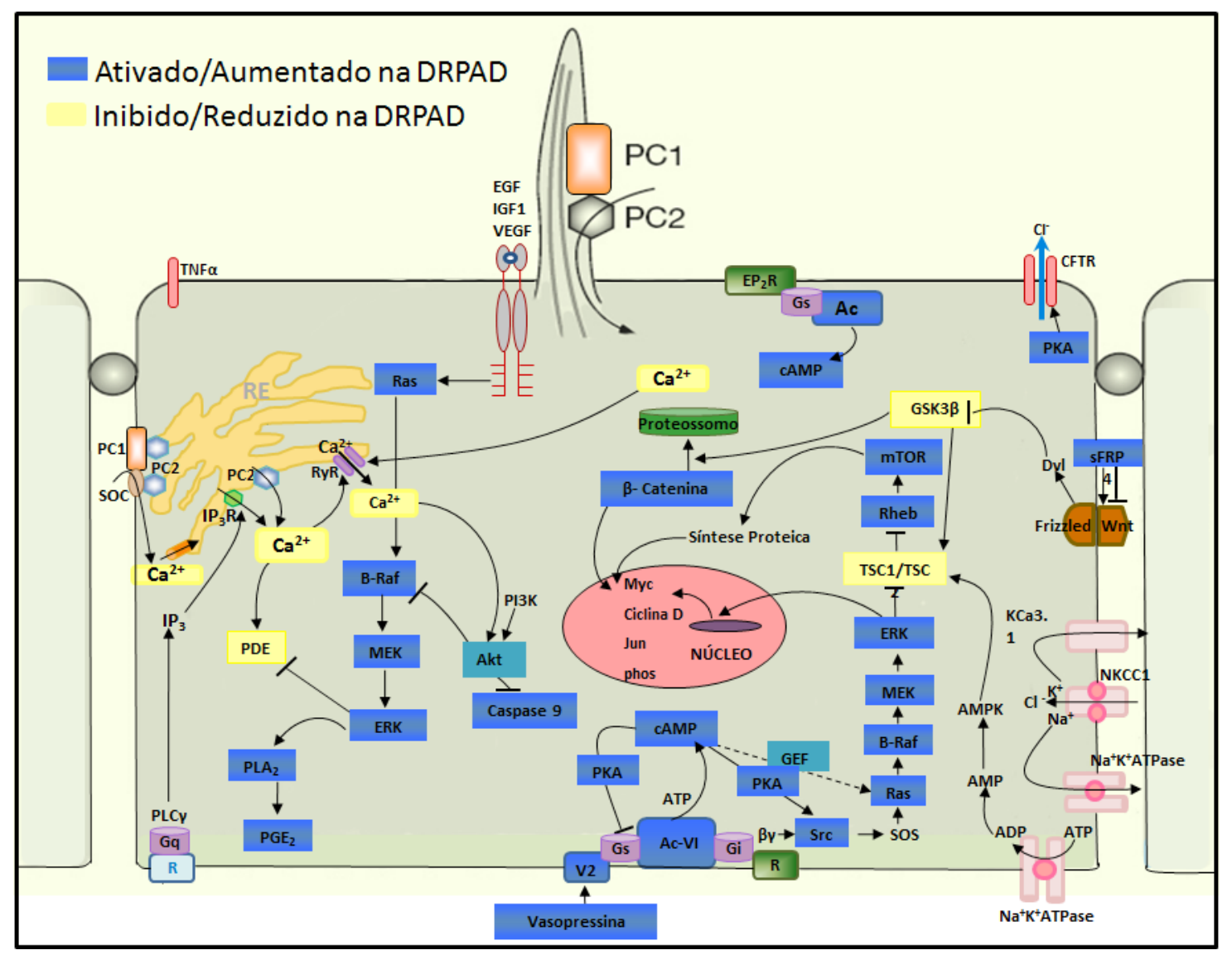

Figura 3: Vias de sinalização alteradas na DRPAD. AC-VI = adenilato ciclase 6; Akt = proteína quinase B; AMPK = AMP quinase; $\mathrm{B}$-Raf $=$ v-raf murine sarcoma viral oncogene homolog B $; \mathrm{CDK}=$ quinase dependente de ciclina; $\mathrm{CFTR}=$ cystic fibrosis transmembrane conductance regulator; $\mathrm{EGF}=$ epidermal growth factor; $\mathrm{EP}_{2} \mathrm{R}=$ E-prostanoid receptor $2 ; \mathrm{ERK}=$ extracellular signal-regulated protein kinase; GSK3 = glycogen synthase kinase 3; IGF1 = insulin-like growth factor 1; IP ${ }_{3} \mathrm{R}=$ receptor inositol 1,4,5-trisfosfato; MAPK $=$ mitogen-activated protein kinase $; \mathrm{mTOR}=$ mammalian target for rapamycin $; \mathrm{PC} 1=$ policistina- $1 ; \mathrm{PC} 2=$ policistina- $;$ PDE $=$ fosfodiesterase; $\mathrm{PGE}_{2}=$ prostaglandina $\mathrm{E} 2 ; \mathrm{PI} 3 \mathrm{~K}=$ phosphatidylinositol 3-kinase $; \mathrm{PKA}=$ proteina quinase $\mathrm{A} ; \mathrm{PLA}_{2}=$ phospholipase A2; $\mathrm{PLC} \gamma=$ fosfolipase $\mathrm{C}-\gamma 2 ; \mathrm{R}=$ somatostatin sst 2 receptor; $\mathrm{Rheb}=$ ras homolog enriched in brain; $\mathrm{RyR}=$ receptoe rianodina; $\mathrm{sFRP} 4$ $=$ secreted Frizzled-related protein 4 ; TK = tirosina quinase; TNF- $\alpha=$ tumor necrosis factor- $\alpha$; TSC $2=$ tuberina; TSC1 = hamartina; $\mathrm{V} 2 \mathrm{R}=$ vasopressin $V 2$ receptor $; \mathrm{VEGF}=$ vascular endothelial growth factor. (Adaptado de esquema usado anteriormente por Ana Paula Bastos e Luiz F. Onuchic, com autorização) ${ }^{109}$ 
PC1 é uma glicoproteína enorme com um complexo perfil de modificações pós-transcricionais. Atualmente, acredita-se que existam duas formas de PC1 na célula: uma madura, processada pelo complexo de Golgi e direcionada para a MP (PC1-NTR), e uma não-madura, que não passa pelo Golgi e permanece retida no citoplasma celular. Recentemente, um estudo demostrou que a formação de PC1-NTR depende de PC2 de forma dose-dependente. Dessa forma, admite-se que PC2 possa atuar como uma chaperona essencial à maturação de PC1 (103). Esse estudo demonstra que além da formação do complexo funcional PC1/PC2, a interação entre essas proteínas pode acontecer em diferentes níveis celulares e moleculares.

Apesar de a DRPAD ser uma doença de transmissão genética dominante, estudos apoiam um mecanismo recessivo para cistogênese. De acordo com esse modelo, a formação cística segue um padrão knudsoniano de dois eventos, descrito inicialmente para genes supressores de tumores. Nesse modelo, o primeiro evento constitui-se na mutação de linhagem germinativa, ao passo que o segundo é representado por uma mutação somática que inativa, ou reduz a atividade, da cópia previamente normal ${ }^{104}$. Esse modelo explica a natureza focal da cistogênese e é consistente com a variabilidade fenotípica observada na DRPAD.

Um importante estudo revelou a existência de uma mudança abrupta de resposta à inativação de ambas as cópias de $P k d 1$ associada à fase de desenvolvimento renal. Utilizando camundongos nocautes condicionais para este gene, Piontek et al. ${ }^{105}$ mostraram que quando a inativação ocorreu antes do $13^{\circ}$ dia de vida os camundongos cursaram com formação cística rápida e intensa, ao passo que a inativação posterior a esta fase acompanhou-se de cistos apenas após cinco meses. Ampliando esse conceito, outros trabalhos sugerem que no rim maduro a inativação de $P k d 1$ não seja suficiente para cistogênese rápida e ampla, requerendo um terceiro evento para deflagrar tal processo $^{106-108}$. Tais resultados ampliaram e aprimoraram o modelo de dois eventos. Neste novo cenário, a cistogênese se inicia em uma dada célula quando a atividade de PC1 ou PC2 cai abaixo de um nível crítico, porém admite-se que este limiar pode variar em função da fase de desenvolvimento renal, variantes genéticas de loci modificadores, fatores ambientais e demandas fisiológicas decorrentes de lesão renal. Resultados advindos do desenvolvimento de animais geneticamente modificados homozigotos para mutações hipomórficas em $P k d 1$ ou $P k d 2$ concordam com tal modelo, apoiando o conceito de limiar de atividade gênica.

\section{Patogênese molecular na DRPAR}

Apesar dos genes causadores da DRPAD e DRPAR serem diferentes e da complexa patogênese molecular da formação de cistos, o epitélio cístico compartilha anormalidades fenotípicas nessas doenças.
Estudos mostraram que o eixo de sinalização EGFR (epidermal growth fator receptor) (MEK/ERK) também está desregulado na DRPAR e que agentes inibidores dessa via melhoram o fenótipo renal ${ }^{110}$ e hepático em modelos animais $^{111}$. Células submetidas ao silenciamento do gene PKHD1 mostraram hiperproliferação e atividade aumentada de ERK1/2 em resposta ao fator de crescimento epidermal (EGF). A resposta hiperproliferativa foi amplificada com o pré-tratamento das células com um bloqueador do canal de cálcio e revertida após elevação de cálcio intracelular. Essa observação demonstrou que, assim como na DRPAD, a resposta hiperproliferativa parece depender da desregulação da homeostase intracelular desse cátion ${ }^{112}$. AMPc também parece ser crucial para a cistogênese na DRPAR. Ratos PCK, modelo ortólogo à DRPAR, tratados com antagonista do receptor da V2 vasopressina, apresentaram redução do nível de AMPc intracelular e diminuição da progressão da doença cística renal ${ }^{113}$.

Utilizando a estratégia de silenciamento gênico por pequenos RNAs de interferência em células mIMCD (mouse inner medullary collecting duct), Mai et al. ${ }^{114}$ mostraram que FPC atua em mecanismos de adesão célular, organização do citoesqueleto de actina, interação com a matriz extracelular, proliferação celular e apoptose. Em concordância com outras ciliopatias, células provenientes de um modelo de camundongo ortólogo à DRPAR humana apresentaram ciliogênese aberrante. Em rins de animais deficientes em Pkhdl observou-se redução marcante da marcação e do comprimento ciliar ${ }^{115}$. Um estudo posterior mostrou, por fim, que a cauda citoplasmática C-terminal de FPC contém uma sequência polipeptídica de endereçamento ciliar ${ }^{116}$.

Evidências acumuladas ao longo dos últimos anos sugerem interação genética entre PKD1, PKD2 e PKHD1. Garcia-Gonzalez e cols demonstraram pela primeira vez interação genética entre $P k d 1$ e $P k h d 1$. Baseados na geração de um alelo $P k h d 1$ hipomórfico, $P k h d 1^{\text {del34 }}$, tais autores mostraram que camundongos $P k d 1^{+/} ; P k h d 1^{\text {del34/del34 }}$ apresentaram manifestações da DRPAR substancialmente

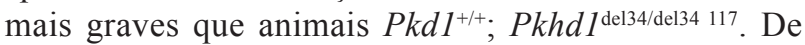
fato, interações entre os produtos proteicos dos genes causadores da DRPAD e DRPAR são observadas no CAP, desmossomos, adesões focais e/ou junções aderentes. Nesse processo, a interação entre FPC e PC2 em um complexo cistoproteico é bem documentada. Utilizando estratégia de deleção e mutagênese dirigida, mostrou-se que a expressão de PC2 é regulada pela interação entre um domínio de ligação a PC2 presente na porção C-terminal intracelular da FPC e um domínio de ligação a FPC localizado na porção N-terminal intracelular da $\mathrm{PC} 2{ }^{118}$. Tal interação é aparentemente capaz de modular respostas mediadas por $\mathrm{Ca}^{2+}$ em epitélio renal e seu comprometimento pode desempenhar um papel importante na patogênese molecular da DRPAR ${ }^{119}$. Vale notar que tal interação e o defeito na homeostase de $\mathrm{Ca}^{2+}$ intracelular também foram 
demonstrados em camundongos knockout para $P k h d 1^{115}$. Merece destaque, por fim, a demonstração in vitro de que FPC sofre um processamento proteolítico semelhante ao da proteína notch, achado que sugere que ela funcione como uma molécula sinalizadora bidirecional. O processo de clivagem libera um grande domínio extracelular, bem como um fragmento C-terminal citoplasmático. A liberação regulada do ectodomínio para a luz tubular pode se constituir em um mecanismo parácrino de distribuição de sinal, baseado no fluxo de fluido tubular. A geração de um gradiente assimétrico de sinal, por sua vez, poderia manter a orientação planar da célula em relação seu eixo longitudinal. Nesse cenário, a desregulação desse mecanismo poderia contribuir para os defeitos de polaridade planar encontrados em células epiteliais do rim na DRPAR ${ }^{120}$. Em apoio a esta hipótese, ratos PCK apresentam defeitos na polaridade celular $^{121}$. Um estudo posterior caracterizou a relevância funcional do fragmento C-terminal da $\mathrm{FPC}^{122}$. Vale notar que a expressão deste fragmento em células epiteliais renais levou à desregulação do ciclo celular e apoptose aumentada em condições de cultivo com baixa concentração de soro fetal bovino. Tais anormalidades podem decorrer da ativação constitutiva de Akt/mTOR em tais células, uma vez que se detectou aumento da fosforilação de Akt e S6 quinase-1. Interessantemente, tal efeito não foi encontrado em células transfectadas com FPC completa.

\section{Patogênese molecular nas NPHPs}

A maior parte das NFCs é expressa no CAP/ $\mathrm{CB}$ de células epiteliais renais. Essas proteínas podem interagir umas com as outras ou com outras cistoproteínas, formando complexos funcionais. Dados proteômicos recentes indicam a formação de ao menos 3 complexos proteicos nefrocísticos: o complexo formado pelas NFCs 1-4-8, localizado na zona de transição ciliar e junções célula-célula, está envolvido na organização estrutural da superfície apical do CAP e na morfogênese epitelial; o complexo formado pelas NFCs 5 e 6 encontra-se localizado no corpo basal e está envolvido na ciliogênese; o complexo formado pelas NFCs 2-3-9, por fim, localiza-se em todo o axonema e interage com os outros dois complexos (40) (Figura 2). As NFCs também interagem com as proteínas relacionadas à MKS e JBTS, sendo esta uma possível explicação para a sobreposição de manifestações clínicas entre essas doenças ${ }^{40}$.

NEK8, a produto do gene $N P H P 9$, interage com PC2. Camundongos deficientes de NEK8 apresentaram expressão aumentada de PC1 e PC2, levando a seu acúmulo ciliar, além de fosforilação anormal de $\mathrm{PC} 2^{123}$. Nessa linha conceitual, mostrou-se interação entre o domínio SH3 de NFC1 e um motivo poliprolina de PC1. Essa interação é capaz de modular apoptose celular, sugerindo que a resistência a apoptose mediada por PC1 possa depender de NFC1 $1^{124}$.

Estudos moleculares mostraram o envolvimento da via Wnt na patogênese das NPHPs. Simons e cols demostraram que NFC2 (inversina) inibe a via canônica Wnt através da regulação da degradação da proteína Dishevelled (Dvl), que em sua forma ativa inibe a degradação de $\beta$-catenina. O aumento da degradação de Dvl leva a uma mudança de sinalização da via Wnt, passando-a predominantemente da forma canônica para a forma não dependente de $\beta$-catenina- via não-canônica ${ }^{125}$. Esse mecanismo parece ser essencial para o desenvolvimento renal normal. Disfunções na inversina ou a ativação constitutiva da Wnt canônica levam à extensa formação cística durante o desenvolvimento embrionário ${ }^{125-127}$. NFC3, por sua vez, pode participar do controle da via Wnt canônica e não canônica. A modulação da via canônica pela NFC3 pode decorrer de sua interação com a inversina ${ }^{128}$. Além disso, deficiência de NFC3 em Xenopus laevis resultou em defeitos de polaridade planar celular, mecanismo tipicamente regulado pela via Wnt não-canônica ${ }^{128}$. De forma semelhante, NFC4 também interage com inversina e controla a via Wnt canônica em zebrafish e em cultura de células renais ${ }^{129}$.

Outra importante via de sinalização ciliar envolvida na patogênese da NPHC é a via Sonic Hedgehog (Shh). Essa via é essencial durante a embriogênese, atuando na diferenciação e especialização celular. A ativação desta via depende da ligação de Hedgehog $(\mathrm{Hh})$ ao seu receptor de membrana Patched-1 (PTCH1). Essa ligação bloqueia o efeito inibitório de PTCH1 sobre a proteína Smoothened (SMO), que ativa fatores de transcrição da família GLI e deflagra a transcrição de genes responsivos a Shh. NPHP7, um dos genes mutados na NPHP, codifica o fator de transcrição GLIS2. A deficiência dessa proteína leva a uma mudança de perfil transcricional que resulta no aumento da expressão de genes relacionados à indução de transição epitélio-mesenquimal. Este perfil de expressão gênica, por sua vez, induz aumento de apoptose e da fibrose em modelo animal ${ }^{130}$. Um segundo estudo mostrou que camundongos carreadores de mutação em NPHP6 apresentaram manifestações compatíveis com JBTS e aumento de uma proteína inibitória do fator de transcrição GLI3, sugerindo sinalização anormal da via Shh. Esses animais apresentaram ainda alterações estruturais no CAP, defeito revertido pelo tratamento com agonista do ligante $\mathrm{Hh}^{131}$. As NFCs também podem regular outras vias sinalizadoras, como a Hippo ${ }^{132}$ e DDR (DNA damage response signalling) ${ }^{133}$.

O conhecimento acumulado nas últimas duas décadas trouxe um novo contexto molecular e celular às nefropatias hereditárias císticas. Diante da identificação de genes mutados nessas enfermidades e da caracterização de seus produtos proteicos, o processo de elucidação de mecanismos envolvidos em sua patogênese tem sido progressivo e constante. Como consequência, tal 
plataforma de conhecimentos tem permitido a evolução de métodos diagnósticos e amparado estudos pré-clínicos fundamentais, vários dos quais já capazes de sustentar a realização de estudos clínicos capitais. Esta nova realidade

\section{REFERÊNCIAS}

1. Loftus H, Ong AC. Cystic kidney diseases: many ways to form a cyst. Pediatric Nephrol. 2013;28(1):33-49. doi: 10.1007/ s00467-012-2221-x.

2. Ong AC, Devuyst O, Knebelmann B, Walz G, Diseases E-EWGfIK. Autosomal dominant polycystic kidney disease: the changing face of clinical management. Lancet. 2015;385(9981):1993-2002. doi: 10.1016/S01406736(15)60907-2.

3. Zerres K, Mücher G, Becker J, Steinkamm C, RudnikSchöneborn S, Heikkilä P, et al. Prenatal diagnosis of autosomal recessive polycystic kidney disease (ARPKD): molecular genetics, clinical experience, and fetal morphology. Am J Med Genet. 1998;76(2):137-44. doi: 10.1002/(SICI)10968628(19980305)76:2<137::AID-AJMG6>3.0.CO;2-Q.

4. Hildebrandt F, Attanasio M, Otto E. Nephronophthisis: disease mechanisms of a ciliopathy. J Am Soc Nephrol JASN. 2009;20(1):23-35. doi: 10.1681/ASN.2008050456.

5. Wolf MT, Hildebrandt F. Nephronophthisis. Pediatric Nephrol. 2011;26(2):181-94. doi: 10.1007/s00467-010-1585-z.

6. Cramer MT, Guay-Woodford LM. Cystic kidney disease: a primer. Adv Chronic Kidney Dis. 2015;22(4):297-305. doi: 10.1053/j.ackd.2015.04.001.

7. Quinlan RJ, Tobin JL, Beales PL. Modeling ciliopathies: Primary cilia in development and disease. Curr Top Dev Biol. 2008;84:249-310. doi: 10.1016/S0070-2153(08)00605-4.

8. Torres VE, Harris PC. Autosomal dominant polycystic kidney disease: the last 3 years. Kidney Int. 2009;76(2):149-68. doi: 10.1038/ki.2009.128.

9. Gabow PA. Autosomal dominant polycystic kidney disease. N Engl J Med. 1993;329(5):332-42. doi: 10.1056/ NEJM199307293290508.

10. PKD Fountation. Policystic Kidney Disease 2015. Available from: http://www.pkdcure.org/.

11. Perrone RD, Ruthazer R, Terrin NC. Survival after endstage renal disease in autosomal dominant polycystic kidney disease: contribution of extrarenal complications to mortality. Am J Kidney Dis. 2001;38(4):777-84. doi: 10.1053/ ajkd.2001.27720.

12. Ecder T, Schrier RW. Cardiovascular abnormalities in autosomal-dominant polycystic kidney disease. Nat Rev Nephrol. 2009;5(4):221-8. doi: 10.1038/nrneph.2009.13.

13. Chapman AB, Schrier RW. Pathogenesis of hypertension in autosomal dominant polycystic kidney disease. Semin Nephrol. 1991;11(6):653-60.

14. Ecder T, Schrier RW. Hypertension in autosomal-dominant polycystic kidney disease: early occurrence and unique aspects. J Am Soc Nephrol. 2001;12(1):194-200. Available from: http://jasn.asnjournals.org/content/12/1/194.long.

15. Kelleher CL, McFann KK, Johnson AM, Schrier RW. Characteristics of hypertension in young adults with autosomal dominant polycystic kidney disease compared with the general U.S. population. Am J Hypertens. 2004;17(11 Pt 1):1029-34 abre perspectivas médicas promissoras, projetando para novos pacientes afetados por várias dessas doenças um cenário de vida bastante mais otimista que o de doentes pertencentes às gerações anteriores.

16. Fonseca JM, Bastos AP, Amaral AG, Sousa MF, Souza LE, Malheiros DM, et al. Renal cyst growth is the main determinant for hypertension and concentrating deficit in Pkd1-deficient mice. Kidney Int. 2014;85(5):1137-50.

17. Chapman AB, Stepniakowski K, Rahbari-Oskoui F. Hypertension in autosomal dominant polycystic kidney disease. Adv Chronic Kidney Dis. 2010;17(2):153-63.

18. Paavola J, Schliffke S, Rossetti S, Kuo IY, Yuan S, Sun Z, et al. Polycystin-2 mutations lead to impaired calcium cycling in the heart and predispose to dilated cardiomyopathy. J Mol Cell Cardiol. 2013;58:199-208.

19. Balbo BEP. Camundongos com deficiência em $P k d l$ apresentam disfunção cardíaca, fenótipo atenuado por knockout de galectina-3. Universidade de São Paulo; 2014.

20. Barua M, Cil O, Paterson AD, Wang K, He N, Dicks E, et al. Family history of renal disease severity predicts the mutated gene in ADPKD. J Am Soc Nephrol. 2009;20(8):1833-8.

21. Hateboer N, v Dijk MA, Bogdanova N, Coto E, SaggarMalik AK, San Millan JL, et al. Comparison of phenotypes of polycystic kidney disease types 1 and 2. European PKD1PKD2 Study Group. Lancet. 1999;353(9147):103-7.

22. Rossetti S, Harris PC. Genotype-phenotype correlations in autosomal dominant and autosomal recessive polycystic kidney disease. J Am Soc Nephrol. 2007;18(5):1374-80.

23. Cornec-Le Gall E, Audrézet MP, Le Meur Y, Chen JM, Férec C. Genetics and pathogenesis of autosomal dominant polycystic kidney disease: 20 years on. Hum Mutat. 2014;35(12):1393-406.

24. Pei Y, Paterson AD, Wang KR, He N, Hefferton D, Watnick $\mathrm{T}$, et al. Bilineal disease and trans-heterozygotes in autosomal dominant polycystic kidney disease. Am J Hum Genet. 2001;68(2):355-63

25. Sousa MV, Amaral AG, Balbo B, Messias F, Castro I, Salemi $\mathrm{V}$, et al., Efeitos do tabagismo sobre os fenótipos renal e cardíaco de camundongos císticos por inativação do gene Pkd1. In: XVIII Congresso Paulista de Nefrologia; 2015.

26. Hartung EA, Guay-Woodford LM. Autosomal recessive polycystic kidney disease: a hepatorenal fibrocystic disorder with pleiotropic effects. Pediatrics. 2014;134(3):e833-45.

27. Guay-Woodford LM, Desmond RA. Autosomal recessive polycystic kidney disease: the clinical experience in North America. Pediatrics. 2003;111(5 Pt 1):1072-80.

28. Bergmann C, Senderek J, Windelen E, Küpper F, Middeldorf I, Schneider F, et al. Clinical consequences of PKHD1 mutations in 164 patients with autosomal-recessive polycystic kidney disease (ARPKD). Kidney Int. 2005;67(3):829-48.

29. Goto M, Hoxha N, Osman R, Wen J, Wells RG, Dell KM. Renin-angiotensin system activation in congenital hepatic fibrosis in the PCK rat model of autosomal recessive polycystic kidney disease. J Pediatr Gastroenterol Nutr. 2010;50(6):639-44.

30. Hoyer PF. Clinical manifestations of autosomal recessive polycystic kidney disease. Curr Opin Pediatr. 2015;27(2):18692. 
31. Sharp AM, Messiaen LM, Page G, Antignac C, Gubler $\mathrm{MC}$, Onuchic LF, et al. Comprehensive genomic analysis of PKHD1 mutations in ARPKD cohorts. J Med Genet. 2005;42(4):336-49.

32. Arbeiter A, Büscher R, Bonzel KE, Wingen AM, Vester $\mathrm{U}$, Wohlschläger $\mathrm{J}$, et al. Nephrectomy in an autosomal recessive polycystic kidney disease (ARPKD) patient with rapid kidney enlargement and increased expression of EGFR. Nephrol Dial Transplant. 2008;23(9):3026-9.

33. Menezes LF, Onuchic LF. Molecular and cellular pathogenesis of autosomal recessive polycystic kidney disease. Braz J Med Biol Res. 2006;39(12):1537-48.

34. Menezes LF, Cai Y, Nagasawa Y, Silva AM, Watkins ML, Da Silva AM, et al. Polyductin, the PKHD1 gene product, comprises isoforms expressed in plasma membrane, primary cilium, and cytoplasm. Kidney Int. 2004;66(4):1345-55.

35. Ward CJ, Yuan D, Masyuk TV, Wang X, Punyashthiti R, Whelan S, et al. Cellular and subcellular localization of the ARPKD protein; fibrocystin is expressed on primary cilia. Hum Mol Genet. 2003;12(20):2703-10.

36. Wang S, Luo Y, Wilson PD, Witman GB, Zhou J. The autosomal recessive polycystic kidney disease protein is localized to primary cilia, with concentration in the basal body area. J Am Soc Nephrol. 2004;15(3):592-602.

37. Kleinknecht CH, R. Nephronophthisis. In: Cameron J, editor. Textbook of clinical nephrotogy. Oxford: Oxford University Pres; 1992. p.2188-97.

38. Salomon R, Saunier S, Niaudet P. Nephronophthisis. Pediatr Nephrol. 2009;24(12):2333-44.

39. Fliegauf M, Benzing T, Omran H. When cilia go bad: cilia defects and ciliopathies. Nature Rev Mol Cell Biol. 2007;8(11):880-93.

40. Wolf MT. Nephronophthisis and related syndromes. Curr Opin Pediatr. 2015;27(2):201-11

41. Puig JG, Miranda ME, Mateos FA, Picazo ML, Jiménez ML, Calvin TS, et al. Hereditary nephropathy associated with hyperuricemia and gout. Arch Intern Med. 1993;153(3):35765.

42. Scolari F, Caridi G, Rampoldi L, Tardanico R, Izzi C, Pirulli $\mathrm{D}$, et al. Uromodulin storage diseases: clinical aspects and mechanisms. Am J Kidney Dis. 2004;44(6):987-99.

43. Scolari F, Izzi C, Ghiggeri GM. Uromodulin: from monogenic to multifactorial diseases. Nephrol Dial Transplant. 2015;30(8):1250-6.

44. Dahan K, Devuyst O, Smaers M, Vertommen D, Loute G, Poux JM, et al. A cluster of mutations in the UMOD gene causes familial juvenile hyperuricemic nephropathy with abnormal expression of uromodulin. J Am Soc Nephrol. 2003;14(11):2883-93.

45. Rampoldi L, Caridi G, Santon D, Boaretto F, Bernascone I, Lamorte G, et al. Allelism of MCKD, FJHN and GCKD caused by impairment of uromodulin export dynamics. Hum Mol Genet. 2003;12(24):3369-84.

46. Zaucke F, Boehnlein JM, Steffens S, Polishchuk RS, Rampoldi L, Fischer A, et al. Uromodulin is expressed in renal primary cilia and UMOD mutations result in decreased ciliary uromodulin expression. Hum Mol Genet. 2010;19(10):1985-97.

47. Bleyer AJ, Kmoch S. Autosomal dominant tubulointerstitial kidney disease: of names and genes. Kidney Int. 2014;86(3):459-61.
48. Bleyer AJ, Kmoch S, Antignac C, Robins V, Kidd K, Kelsoe $\mathrm{JR}$, et al. Variable clinical presentation of an MUC1 mutation causing medullary cystic kidney disease type 1. Clin J Am Soc Nephrol. 2014;9(3):527-35.

49. Kirby A, Gnirke A, Jaffe DB, Barešová V, Pochet N, Blumenstiel B, et al. Mutations causing medullary cystic kidney disease type 1 lie in a large VNTR in MUC1 missed by massively parallel sequencing. Nat Genet. 2013;45(3):299303.

50. Nath S, Mukherjee P. MUC1: a multifaceted oncoprotein with a key role in cancer progression. Trends Mol Med. 2014;20(6):332-42.

51. Bleyer AJ, Hart PS, Kmoch S. Hereditary interstitial kidney disease. Semin Nephrol. 2010;30(4):366-73.

52. Zivna M, Hulkova H, Matignon M, Hodanova K, Vylet'al $\mathrm{P}$, Kalbacova M, et al. Dominant renin gene mutations associated with early-onset hyperuricemia, anemia, and chronic kidney failure. Am J Human Genet. 2009;85(2):20413

53. Bleyer AJ, Zivná M, Hulková H, Hodanová K, Vyletal $\mathrm{P}$, Sikora J, et al. Clinical and molecular characterization of a family with a dominant renin gene mutation and response to treatment with fludrocortisone. Clin Nephrol. 2010;74(6):411-22

54. Zivná $\mathrm{M}$, Hůlková $\mathrm{H}$, Matignon $\mathrm{M}$, Hodanová $\mathrm{K}$, Vylet'al $\mathrm{P}$, Kalbácová M, et al. Dominant renin gene mutations associated with early-onset hyperuricemia, anemia, and chronic kidney failure. Am J Hum Genet. 2009;85(2):204-13.

55. Gribouval O, Gonzales M, Neuhaus T, Aziza J, Bieth E, Laurent $\mathrm{N}$, et al. Mutations in genes in the renin-angiotensin system are associated with autosomal recessive renal tubular dysgenesis. Nat Genet. 2005;37(9):964-8.

56. Coffinier C, Barra J, Babinet C, Yaniv M. Expression of the vHNF1/HNF1beta homeoprotein gene during mouse organogenesis. Mech Dev. 1999;89(1-2):211-3.

57. Bingham $\mathrm{C}$, Hattersley AT. Renal cysts and diabetes syndrome resulting from mutations in hepatocyte nuclear factor-1beta. Nephrol Dial Transplant. 2004;19(11):2703-8.

58. Bingham C, Bulman MP, Ellard S, Allen LI, Lipkin GW, Hoff WG, et al. Mutations in the hepatocyte nuclear factor-1beta gene are associated with familial hypoplastic glomerulocystic kidney disease. Am J Hum Genet. 2001;68(1):219-24.

59. Bellanné-Chantelot C, Clauin S, Chauveau D, Collin P, Daumont M, Douillard C, et al. Large genomic rearrangements in the hepatocyte nuclear factor-1beta (TCF2) gene are the most frequent cause of maturity-onset diabetes of the young type 5. Diabetes. 2005;54(11):3126-32.

60. Edghill EL, Bingham C, Ellard S, Hattersley AT. Mutations in hepatocyte nuclear factor-1beta and their related phenotypes. J Med Genet. 2006;43(1):84-90.

61. Gresh L, Fischer E, Reimann A, Tanguy M, Garbay S, Shao $\mathrm{X}$, et al. A transcriptional network in polycystic kidney disease. Embo J. 2004;23(7):1657-68.

62. Kim JJ, Rini BI, Hansel DE. Von Hippel Lindau syndrome. Adv Exp Med Biol. 2010;685:228-49.

63. Lonser RR, Glenn GM, Walther M, Chew EY, Libutti SK, Linehan WM, et al. von Hippel-Lindau disease. Lancet. 2003;361(9374):2059-67.

64. Bausch B, Jilg C, Glasker S, Vortmeyer A, Lutzen N, Anton $A$, et al. Renal cancer in von Hippel-Lindau disease and related syndromes. Nature Rev Nephrol. 2013;9(9):529-38. 
65. Vogelzang NJ, Stadler WM. Kidney cancer. Lancet. 1998;352(9141):1691-6.

66. Haase VH. The VHL/HIF oxygen-sensing pathway and its relevance to kidney disease. Kidney Int. 2006;69(8):1302-7.

67. Curatolo P, Bombardieri R, Jozwiak S. Tuberous sclerosis. Lancet. 2008;372(9639):657-68.

68. Cudzilo CJ, Szczesniak RD, Brody AS, Rattan MS, Krueger DA, Bissler JJ, et al. Lymphangioleiomyomatosis screening in women with tuberous sclerosis. Chest. 2013;144(2):57885 .

69. Cook JA, Oliver K, Mueller RF, Sampson J. A cross sectional study of renal involvement in tuberous sclerosis. J Med Genet. 1996;33(6):480-4

70. Rakowski SK, Winterkorn EB, Paul E, Steele DJ, Halpern EF, Thiele EA. Renal manifestations of tuberous sclerosis complex: Incidence, prognosis, and predictive factors. Kidney Int. 2006;70(10):1777-82.

71. Dabora SL, Jozwiak S, Franz DN, Roberts PS, Nieto A, Chung J, et al. Mutational analysis in a cohort of 224 tuberous sclerosis patients indicates increased severity of TSC2, compared with TSC1, disease in multiple organs. Am J Hum Genet. 2001;68(1):64-80.

72. Siroky BJ, Yin H, Bissler JJ. Clinical and molecular insights into tuberous sclerosis complex renal disease. Pediatr Nephrol. 2011;26(6):839-52.

73. Brook-Carter PT, Peral B, Ward CJ, Thompson P, Hughes J, Maheshwar MM, et al. Deletion of the TSC2 and PKD1 genes associated with severe infantile polycystic kidney disease--a contiguous gene syndrome. Nat Genet. 1994;8(4):328-32.

74. Shepherd CW, Gomez MR, Lie J, Crowson CS, editors. Causes of death in patients with tuberous sclerosis. Mayo Clinic Proceedings; 1991.

75. Steiner MS, Goldman SM, Fishman EK, Marshall FF. The natural history of renal angiomyolipoma. J Urol. 1993;150(6):1782-6.

76. Hay N, Sonenberg N. Upstream and downstream of mTOR. Genes Dev. 2004;18(16):1926-45.

77. Sparks CA, Guertin DA. Targeting mTOR: prospects for mTOR complex 2 inhibitors in cancer therapy. Oncogene. 2010;29(26):3733-44.

78. Bissler JJ, Kingswood JC, Radzikowska E, Zonnenberg BA, Frost M, Belousova E, et al. Everolimus for angiomyolipoma associated with tuberous sclerosis complex or sporadic lymphangioleiomyomatosis (EXIST-2): a multicentre, randomised, double-blind, placebo-controlled trial. Lancet. 2013;381(9869):817-24.

79. Kobayashi T, Dynlacht BD. Regulating the transition from centriole to basal body. J Cell Biol. 2011;193(3):435-44

80. Davenport JR, Yoder BK. An incredible decade for the primary cilium: a look at a once-forgotten organelle. Am J Physiol Renal Physiol. 2005;289(6):F1159-69.

81. Nachury MV, Seeley ES, Jin H. Trafficking to the ciliary membrane: how to get across the periciliary diffusion barrier? Annu Rev Cell Dev Biol. 2010;26:59-87.

82. Madhivanan K, Aguilar RC. Ciliopathies: the trafficking connection. Traffic. 2014;15(10):1031-56.

83. Kee HL, Dishinger JF, Blasius TL, Liu CJ, Margolis B, Verhey KJ. A size-exclusion permeability barrier and nucleoporins characterize a ciliary pore complex that regulates transport into cilia. Nat Cell Biol. 2012;14(4):431-7.
84. Ounjai P, Kim KD, Liu H, Dong M, Tauscher AN, Witkowska $\mathrm{HE}$, et al. Architectural insights into a ciliary partition. Curr Biol. 2013;23(4):339-44.

85. Reiter JF, Blacque OE, Leroux MR. The base of the cilium: roles for transition fibres and the transition zone in ciliary formation, maintenance and compartmentalization. EMBO Rep. 2012;13(7):608-18.

86. Blacque OE, Reardon MJ, Li C, McCarthy J, Mahjoub MR, Ansley SJ, et al. Loss of C. elegans BBS-7 and BBS-8 protein function results in cilia defects and compromised intraflagellar transport. Genes Dev. 2004;18(13):1630-42.

87. Ou G, Blacque OE, Snow JJ, Leroux MR, Scholey JM. Functional coordination of intraflagellar transport motors. Nature. 2005;436(7050):583-7.

88. Kim JC, Badano JL, Sibold S, Esmail MA, Hill J, Hoskins BE, et al. The Bardet-Biedl protein BBS4 targets cargo to the pericentriolar region and is required for microtubule anchoring and cell cycle progression. Nat Genet. 2004;36(5):462-70

89. Nachury MV, Loktev AV, Zhang Q, Westlake CJ, Peränen J, Merdes A, et al. A core complex of BBS proteins cooperates with the GTPase Rab8 to promote ciliary membrane biogenesis. Cell. 2007;129(6):1201-13.

90. Jin H, White SR, Shida T, Schulz S, Aguiar M, Gygi SP, et al. The conserved Bardet-Biedl syndrome proteins assemble a coat that traffics membrane proteins to cilia. Cell. 2010;141(7):1208-19

91. Seo S, Guo DF, Bugge K, Morgan DA, Rahmouni K, Sheffield VC. Requirement of Bardet-Biedl syndrome proteins for leptin receptor signaling. Hum Mol Genet. 2009;18(7):1323-31.

92. Nauli SM, Alenghat FJ, Luo Y, Williams E, Vassilev P, Li X, et al. Polycystins 1 and 2 mediate mechanosensation in the primary cilium of kidney cells. Nat Genet. 2003;33(2):12937.

93. Praetorius HA, Spring KR. The renal cell primary cilium functions as a flow sensor. Curr Opin Nephrol Hypertens. 2003;12(5):517-20.

94. Yamaguchi T, Hempson SJ, Reif GA, Hedge AM, Wallace DP. Calcium restores a normal proliferation phenotype in human polycystic kidney disease epithelial cells. J Am Soc Nephrol. 2006;17(1):178-87.

95. Li H, Findlay IA, Sheppard DN. The relationship between cell proliferation, Cl- secretion, and renal cyst growth: a study using CFTR inhibitors. Kidney Int. 2004;66(5):192638.

96. Roitbak T, Ward CJ, Harris PC, Bacallao R, Ness SA, Wandinger-Ness A. A polycystin-1 multiprotein complex is disrupted in polycystic kidney disease cells. Mol Biol Cell. 2004;15(3):1334-46.

97. Silberberg M, Charron AJ, Bacallao R, WandingerNess A. Mispolarization of desmosomal proteins and altered intercellular adhesion in autosomal dominant polycystic kidney disease. Am J Physiol Renal Physiol. 2005;288(6):F1153-63

98. Bhunia AK, Piontek K, Boletta A, Liu L, Qian F, Xu PN, et al. PKD1 induces $\mathrm{p} 21$ (wafl) and regulation of the cell cycle via direct activation of the JAK-STAT signaling pathway in a process requiring PKD2. Cell. 2002;109(2):157-68.

99. Shillingford JM, Murcia NS, Larson CH, Low SH, Hedgepeth R, Brown N, et al. The mTOR pathway is regulated by polycystin- 1 , and its inhibition reverses renal 
cystogenesis in polycystic kidney disease. Proc Natl Acad Sci U S A. 2006;103(14):5466-71.

100. Dere R, Wilson PD, Sandford RN, Walker CL. Carboxy terminal tail of polycystin-1 regulates localization of TSC2 to repress mTOR. PLoS One. 2010;5(2):e9239.

101. Weimbs T. Regulation of mTOR by polycystin-1: is polycystic kidney disease a case of futile repair? Cell Cycle. 2006;5(21):2425-9.

102. Distefano G, Boca M, Rowe I, Wodarczyk C, Ma L, Piontek $\mathrm{KB}$, et al. Polycystin-1 regulates extracellular signalregulated kinase-dependent phosphorylation of tuberin to control cell size through mTOR and its downstream effectors S6K and 4EBP1. Mol Cell Biol. 2009;29(9):2359-71.

103. Gainullin VG, Hopp K, Ward CJ, Hommerding CJ, Harris PC. Polycystin-1 maturation requires polycystin- 2 in a dose-dependent manner. J Clin Invest. 2015;125(2):607-20.

104. Qian F, Watnick TJ, Onuchic LF, Germino GG. The molecular basis of focal cyst formation in human autosomal dominant polycystic kidney disease type I. Cell. 1996;87(6):979-87.

105. Piontek K, Menezes LF, Garcia-Gonzalez MA, Huso DL, Germino GG. A critical developmental switch defines the kinetics of kidney cyst formation after loss of Pkd1. Nat Med. 2007;13(12):1490-5.

106. Bastos AP, Piontek K, Silva AM, Martini D, Menezes LF, Fonseca JM, et al. Pkd1 haploinsufficiency increases renal damage and induces microcyst formation following ischemia/reperfusion. J Am Soc Nephrol. 2009;20(11):2389402.

107. Lantinga-van Leeuwen IS, Leonhard WN, van der Wal A, Breuning MH, de Heer E, Peters DJ. Kidney-specific inactivation of the Pkd1 gene induces rapid cyst formation in developing kidneys and a slow onset of disease in adult mice. Hum Mol Genet. 2007;16(24):3188-96.

108. Takakura A, Contrino L, Beck AW, Zhou J. Pkd1 inactivation induced in adulthood produces focal cystic disease. J Am Soc Nephrol. 2008;19(12):2351-63.

109. Bastos AP, Onuchic LF. Molecular and cellular pathogenesis of autosomal dominant polycystic kidney disease. Braz J Med Biol Res. 2011;44(7):606-17.

110. Richards WG, Sweeney WE, Yoder BK, Wilkinson JE, Woychik RP, Avner ED. Epidermal growth factor receptor activity mediates renal cyst formation in polycystic kidney disease. J Clin Invest. 1998;101(5):935-9.

111. Sato Y, Harada K, Kizawa K, Sanzen T, Furubo S, Yasoshima M, et al. Activation of the MEK5/ERK5 cascade is responsible for biliary dysgenesis in a rat model of Caroli's disease. Am J Pathol. 2005;166(1):49-60.

112. Yang J, Zhang S, Zhou Q, Guo H, Zhang K, Zheng R, et al. PKHD1 gene silencing may cause cell abnormal proliferation through modulation of intracellular calcium in autosomal recessive polycystic kidney disease. J Biochem Mol Biol. 2007;40(4):467-74.

113. Gattone VH, Wang X, Harris PC, Torres VE. Inhibition of renal cystic disease development and progression by a vasopressin V2 receptor antagonist. Nat Med. 2003;9(10):1323-6.

114. Mai W, Chen D, Ding T, Kim I, Park S, Cho SY, et al. Inhibition of Pkhd1 impairs tubulomorphogenesis of cultured IMCD cells. Mol Biol Cell. 2005;16(9):4398-409.

115. Kim I, Fu Y, Hui K, Moeckel G, Mai W, Li C, et al.
Fibrocystin/polyductin modulates renal tubular formation by regulating polycystin-2 expression and function. J Am Soc Nephrol. 2008;19(3):455-68.

116. Follit JA, Li L, Vucica Y, Pazour GJ. The cytoplasmic tail of fibrocystin contains a ciliary targeting sequence. J Cell Biol. 2010;188(1):21-8.

117. Garcia-Gonzalez MA, Menezes LF, Piontek KB, Kaimori J, Huso DL, Watnick T, et al. Genetic interaction studies link autosomal dominant and recessive polycystic kidney disease in a common pathway. Hum Mol Genet. 2007;16(16):194050 .

118. Kim I, Li C, Liang D, Chen XZ, Coffy RJ, Ma J, et al. Polycystin-2 expression is regulated by a PC2-binding domain in the intracellular portion of fibrocystin. J Biol Chem. 2008;283(46):31559-66.

119. Wang S, Zhang J, Nauli SM, Li X, Starremans PG, Luo $\mathrm{Y}$, et al. Fibrocystin/polyductin, found in the same protein complex with polycystin-2, regulates calcium responses in kidney epithelia. Mol Cell Biol. 2007;27(8):3241-52.

120. Kaimori JY, Nagasawa Y, Menezes LF, Garcia-Gonzalez MA, Deng J, Imai E, et al. Polyductin undergoes notch-like processing and regulated release from primary cilia. Hum Mol Genet. 2007;16(8):942-56.

121. Fischer E, Legue E, Doyen A, Nato F, Nicolas JF, Torres $\mathrm{V}$, et al. Defective planar cell polarity in polycystic kidney disease. Nat Genet. 2006;38(1):21-3.

122. Wang S, Wu M, Yao G, Zhang J, Zhou J. The cytoplasmic tail of FPC antagonizes the full-length protein in the regulation of mTOR pathway. PLoS One. 2014;9(5):e95630.

123. Sohara E, Luo Y, Zhang J, Manning DK, Beier DR, Zhou J. Nek8 regulates the expression and localization of polycystin-1 and polycystin-2. J Am Soc Nephrol. 2008;19(3):469-76.

124. Wodarczyk C, Distefano G, Rowe I, Gaetani M, Bricoli B, Muorah M, et al. Nephrocystin-1 forms a complex with polycystin-1 via a polyproline motif/SH3 domain interaction and regulates the apoptotic response in mammals. PLoS One. 2010;5(9):e12719.

125. Simons M, Gloy J, Ganner A, Bullerkotte A, Bashkurov $\mathrm{M}$, Krönig $\mathrm{C}$, et al. Inversin, the gene product mutated in nephronophthisis type II, functions as a molecular switch between Wnt signaling pathways. Nat Genet. 2005;37(5):537-43.

126. Saadi-Kheddouci S, Berrebi D, Romagnolo B, Cluzeaud F, Peuchmaur M, Kahn A, et al. Early development of polycystic kidney disease in transgenic mice expressing an activated mutant of the beta-catenin gene. Oncogene. 2001;20(42):5972-81.

127. Qian CN, Knol J, Igarashi P, Lin F, Zylstra U, Teh BT, et al. Cystic renal neoplasia following conditional inactivation of apc in mouse renal tubular epithelium. J Biol Chem. 2005;280(5):3938-45.

128. Bergmann C, Fliegauf M, Brüchle NO, Frank V, Olbrich $\mathrm{H}$, Kirschner J, et al. Loss of nephrocystin-3 function can cause embryonic lethality, Meckel-Gruber-like syndrome, situs inversus, and renal-hepatic-pancreatic dysplasia. Am J Hum Genet. 2008;82(4):959-70.

129. Burcklé C, Gaudé HM, Vesque C, Silbermann F, Salomon $\mathrm{R}$, Jeanpierre $\mathrm{C}$, et al. Control of the Wnt pathways by nephrocystin- 4 is required for morphogenesis of the zebrafish pronephros. Hum Mol Genet. 2011;20(13):261127. 
130. Attanasio M, Uhlenhaut NH, Sousa VH, O'Toole JF, Otto E, Anlag K, et al. Loss of GLIS2 causes nephronophthisis in humans and mice by increased apoptosis and fibrosis. Nat Genet. 2007;39(8):1018-24.

131. Hynes AM, Giles RH, Srivastava S, Eley L, Whitehead J, Danilenko M, et al. Murine Joubert syndrome reveals Hedgehog signaling defects as a potential therapeutic target for nephronophthisis. Proc Natl Acad Sci U S A. 2014;111(27):9893-8.
132. Frank V, Habbig S, Bartram MP, Eisenberger T, VeenstraKnol HE, Decker C, et al. Mutations in NEK8 link multiple organ dysplasia with altered Hippo signalling and increased c-MYC expression. Hum Mol Genet. 2013;22(11):2177-85.

133. Chaki M, Airik R, Ghosh AK, Giles RH, Chen R, Slaats GG, et al. Exome capture reveals ZNF423 and CEP164 mutations, linking renal ciliopathies to DNA damage response signaling. Cell. 2012;150(3):533-48. 